\title{
Communicating changes in state of the southern Benguela ecosystem using trophic, model-derived indicators
}

\author{
L. J. Shannon ${ }^{1, *}$, W. Osman ${ }^{1,2}$, A. Jarre ${ }^{1}$ \\ ${ }^{1}$ Marine Research Institute and Department of Biological Sciences, University of Cape Town, Private Bag X3, \\ Rondebosch 7701, South Africa \\ ${ }^{2}$ Present address: Environmental Management Services (EMS), CSIR, PO Box 320, Stellenbosch 7599, South Africa
}

\begin{abstract}
An updated trophic model of the southern Benguela ecosystem in the period 2004-2008 was constructed, complementing trophic models for earlier periods. The model represents the trophic structure of the system after a southward shift of major resources. There was an increase in biomass of small pelagic fish and cephalopods between the 1980s and 2004-2008 periods, accompanied by declines in several higher trophic level groups. A 3 step process was followed: (1) a series of snapshots of the ecosystem was used to explore changes in the food web structure over time, (2) trophic indicators were extracted from these models to detect changes, and (3) model-derived ecological indicators which were deemed most meaningful for management within the ecosystem were selected for use in decision trees, providing a logical framework in which to access synthesised information on trends in ecosystem status as a result of fishing. Three decision trees were developed which examined the ecosystem at the community level (pelagiccaught fish and demersal-caught fish community decision trees) and at the system level (ecosystem decision tree). The decision trees classified one period of the southern Benguela ecosystem as 'Deteriorating' (the period after the onset of industrial fishing: 1960s vs. 1900s), and 3 periods as 'Not improving' (1980s vs. 1960s, 1990s vs. 1980s, and 2004-2008 vs. 1980s). The current management strategy has ensured that the offshore southern Benguela ecosystem has not deteriorated further since the 1960s in terms of ecosystem functioning and at the scale of the fish community. Although the decision trees are conservative with regard to trends, the logic they employ is sound and robust, providing fisheries managers with a coherent framework to access synthesised information and the reasoning behind conclusions reached.
\end{abstract}

KEY WORDS: Trophic model $\cdot$ Food web $\cdot$ Southern Benguela $\cdot$ Upwelling system $\cdot$ Ecosystem state $\cdot$ Effects of fishing $\cdot$ Fisheries management

Resale or republication not permitted without written consent of the publisher

\section{INTRODUCTION}

Fisheries management is still largely based on single-species considerations, whereas an ecosystem perspective has been identified as important for a more holistic management approach (the 1995 FAO Code of Conduct for Responsible Fisheries; the 2001 Reykjavík Declaration on Responsible Fisheries in the Marine Ecosystem; the 2002 World Summit for Sustainable Development held in Johannesburg, South Africa). An ecosystem approach to fisheries (EAF) is defined as 'the development and management of fisheries in a manner that addresses the multiple needs and desires of societies, without jeopardizing the options for future generations to benefit from the full range of goods and services provided by marine ecosystems' (FAO 2003, p. 14). South Africa is committed to implement an ecosystem approach in its domestic fisheries (Cochrane et al. 2004), as well as being a member of the Benguela Current Commission (Cochrane et al. 2009). 
Although the concepts of an EAF are now widely accepted, the sound implementation thereof remains a considerable challenge (Cochrane et al. 2004, 2009). An integral part of implementing an EAF is communication among stakeholders, which has been highlighted as one of the historic shortcomings in fisheries management (FAO 2003). To facilitate the process of communication, information from models and data studies is often synthesized into indicators. Indicators are system characteristics which provide feedback on progress towards management objectives (Slocombe 1998), and have been recognised as a necessary basis for the implementation of an EAF (Degnbol \& Jarre 2004, Daan et al. 2005 and contributors therein, FAO 2005). Degnbol \& Jarre (2004) emphasised that indicators should be selected on the basis of those that are accepted by, and communicable among, stakeholders. Data-based indicators for the assessment of ecosystem states and trends at the community and ecosystem scales have been scrutinised in the IndiSeas project (Shin \& Shannon 2010). Model-based indicators bear similar potential if based on good quality models (Fulton et al. 2005). For the southern Benguela ecosystem, indicators from a suite of trophic models is available for analysis of long-term, large-scale changes in state (Shannon et al. 2003, 2009a, Watermeyer et al. 2008).

\section{The southern Benguela ecosystem}

The southern Benguela is an eastern boundary upwelling ecosystem located along the west coast of South Africa (Fig. 1). For management and modelling purposes, it is considered to extend from the South African Orange River border with Namibia $\left(29^{\circ} \mathrm{S}\right)$ on the west coast, to East London on the south coast $\left(28^{\circ} \mathrm{E}\right.$ ), covering an area of $220000 \mathrm{~km}^{2}$ (Shannon et al. 2003). The marine fauna in the ecosystem is particularly rich (Gibbons et al. 1999), and due to its productivity, the southern Benguela ecosystem is able to support a number of commercial fisheries including small pelagic fish, large pelagic fish and hake. Variability in the natural system is high on a variety of scales, ranging from monthly to decadal, and predictability of its dynamics is a matter of ongoing research (e.g. Shannon et al. 2006, Travers \& Shin 2010).

In the second half of the 1990s, a shift in the relative distribution of small pelagic fish (anchovy and sardine) took place (van der Lingen et al. 2002, 2006, Fairweather et al. 2006), which lasted until the second half of the 2000s and is hypothe-

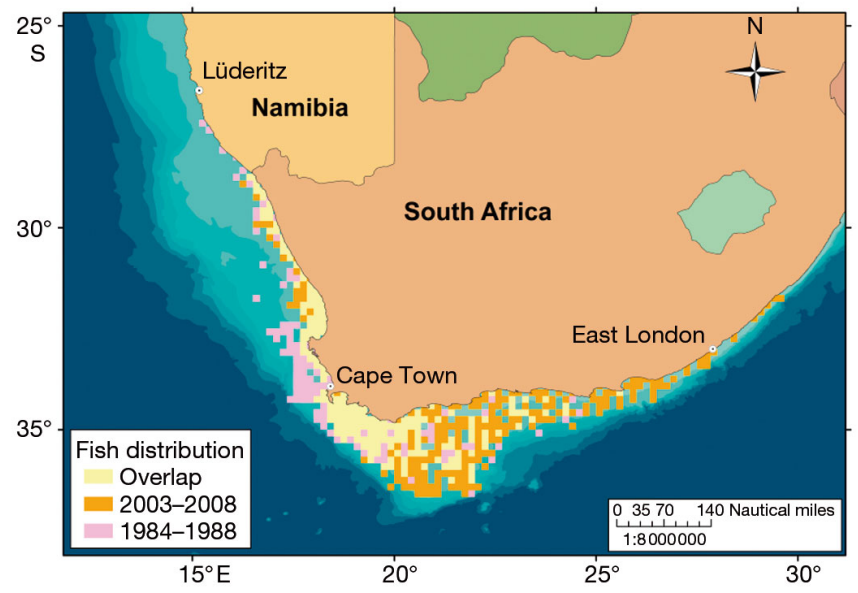

Fig. 1. Southern Benguela ecosystem $\left(29^{\circ} \mathrm{S}\right.$ to $\left.28^{\circ} \mathrm{E}\right)$ and the distribution of small pelagic fish (anchovy and sardine) within the system during the 1980s and the 2003-2008 periods. Distribution patterns provided by K. Watermeyer, University of Cape Town, based on unpublished pelagic research survey data from the South African Department of Forestry and Fisheries. These distribution patterns represent $95 \%$ of small pelagic fish biomass surveyed (combined yearly summer and autumn surveys). Survey areas along the west coast between the 2 time periods overlap. However, survey areas along the south coast were extended further eastwards along the coast from the 2000s, in response to reports of small pelagic fish catches from these previously unsurveyed areas (K. Watermeyer, UCT, pers. comm.)

sised to have been a result of changing environmental conditions (Howard et al. 2007, Roy et al. 2007, Blamey et al. 2012). A smaller proportion than previously of small pelagic fish were distributed along the west coast and a larger proportion along the south coast during the period examined in this study (2004 to 2008). These changes rang warning bells with marine ecologists, because the south coast is generally regarded as less productive than the west coast (Demarq et al. 2008) but supporting a number of potential predators of small pelagic fish. The possibility of an ecosystem regime shift was postulated (Howard et al. 2007, Blamey et al. 2012). Regime shifts signify a complete change in ecosystem status and function (Collie et al. 2004), which is different to the phenomenon of species alternations previously described in the southern Benguela ecosystem from the 1980s to the 1990s (Cury \& Shannon 2004). Over the long-term, largescale changes in the functioning of an ecosystem may require fisheries management to be carried out differently, as such changes increase the potential for collapses of target stocks due to changes in the functioning of the ecosystem (Rothschild \& Shannon 2004, Shannon et al. 2009b). 


\section{Trophic models and corresponding indicators}

Using the Ecopath with Ecosim (EwE) approach (Christensen \& Walters 2004), models can be constructed to represent the ecosystem and the flows (trophic interactions) between components, thus allowing scientists and managers to view potential ecosystem state scenarios in relation to alternative fishing strategies (Pauly et al. 2000). In this study, an updated trophic model of the southern Benguela ecosystem is presented, representing the period 2004-2008, complementing trophic models for past periods of the southern Benguela ecosystem published by Shannon et al. (2003) and Watermeyer et al. (2008), namely the 1900s 'pristine', 1960s 'industrial', 1980s 'anchovy' and 1990s 'sardine recovery' periods. Thus, a series of models of regimespecific trophic structure is available, describing the southern Benguela ecosystem from the largely unfished era to the period during which geographical shifts in some fish resources occurred (Osman 2010). Key results are presented comparing the ecosystem characteristics and state across the different periods. Trophic indicators can be derived from these models for possible management consideration. The information that can be gained from a set of indicators such as this can be summarised into decision trees; in this study we feed the trophic indicators into 3 decisions trees to classify trends in the southern Benguela ecosystem, with the aim of capturing ecosystem responses to fishing in particular. The study serves as a step towards improving communication among scientists and fishery managers on indicators at a scale different to that of current practice, namely the scale of fish communities and the ecosystem that supports important fisheries in the southern Benguela ecosystem.

\section{METHODS}

\section{Model construction}

The southern Benguela ecosystem in the period 2004-2008 was modelled using the EwE software version 5.1 (Polovina 1984, Pauly et al. 2000). The software is designed for the construction, parameterisation and analysis of mass-balanced trophic models of ecosystems (Pauly et al. 2000, Christensen \& Walters 2004, Christensen et al. 2005). This particular version of EwE was used to facilitate comparisons with previously published models (Shannon et al. 2003, Watermeyer et al. 2008).
Thirty-one living groups and a detritus group were parameterised for the period 2004-2008. Initial input parameters and data sources for the living groups are provided in Tables $\mathrm{S} 1-\mathrm{S} 4$ in Supplement 1 (www.int-res.com/articles/suppl/m512p217_supp.pdf), and modifications to phytoplankton and chub mackerel model biomass, and snoek Thrysites atun and cephalopod model diets for model balancing are also recorded (Tables S1-S4 in Supplement 1). Biomass estimates for demersally surveyed groups excludes the year 2006 because different trawl gear was used from that in 2004-2005 and 2007-2008. The data from 2006 are not readily comparable with the other 4 years (Atkinson et al. 2012). Final parameter values adopted in the balanced trophic model for the southern Benguela ecosystem representing the period 2004-2008 are tabulated (Table 1). The 2004-2008 model was compared to models of previous time periods, i.e. past ecosystem states. The 3 historic time periods examined were the 1900s 'pristine', the 1960s 'industrial' and 1980s 'anchovy' periods. The 1900s and 1960s models were compiled by Watermeyer et al. (2008) and the 1980s model was constructed by Shannon et al. (2003).

\section{Trophic indicator selection}

Changes occurring within and across the functional groups can be related to changes in ecosystem structure and function (Cury et al. 2005). After Cury et al. (2005) and Shannon et al. (2009a), model groups were aggregated to form functional groups describing important ecosystem components (Table 2). The functional groups PEL and DEM were largely separated according to the type of fishery in which fish were caught, i.e. pelagic fishery (purse-seine, linefishery, long line, other) or demersal fishery (midwater trawl, demersal trawl, long line, other). Indicators generated from model outputs express ecosystem properties not usually available through the data-based indicators extracted from research surveys. These include production and consumption ratios, which are important for understanding the underlying dynamics of the system (Cury et al. 2005), thus providing a more complete picture of the ecosystem and its properties. Eight groups of indicators were initially extracted: biomass (B), production $(\mathrm{P})$, consumption $(\mathrm{C})$, catch $(\mathrm{Y})$, trophic level $(\mathrm{TL})$, turnover rate $(\mathrm{P} / \mathrm{B})$, catch/production $(\mathrm{Y} / \mathrm{P})$, catch/biomass (Y/B). Model-estimated B, P, C, Y, $\mathrm{P} / \mathrm{B}$ and TL ratios were calculated to compare functional groups within the southern Benguela ecosys- 
Table 1. Balanced trophic model of the southern Benguela ecosystem for the period 2004-2008. Input parameters are in bold; all other values were estimated by the model. $\mathrm{TL}=$ trophic level $; \mathrm{B}=$ biomass $; \mathrm{Y}=$ catch; $\mathrm{EE}=$ ecotrophic efficiency. $M .=$ Merluccius

\begin{tabular}{|lcccc|}
\hline Model group & $\mathrm{TL}$ & $\begin{array}{c}\mathrm{B} \\
\left(\mathrm{km}^{-2}\right)\end{array}$ & $\begin{array}{c}\mathrm{Y} \\
\left(\mathrm{t} \mathrm{km}^{-2} \mathrm{yr}^{-1}\right)\end{array}$ & $\mathrm{EE}$ \\
\hline Phytoplankton & & 91.333 & $\mathbf{0}$ & $\mathbf{0 . 6 7 6}$ \\
Benthic producers & 1 & 7.232 & $\mathbf{0}$ & $\mathbf{0 . 5 0 0}$ \\
Microzooplankton & 2.25 & 10.492 & $\mathbf{0}$ & $\mathbf{0 . 9 5 0}$ \\
Mesozooplankton & 2.63 & 10.974 & $\mathbf{0}$ & $\mathbf{0 . 9 5 0}$ \\
Macrozooplankton & 2.65 & 16.565 & $\mathbf{0}$ & $\mathbf{0 . 9 5 0}$ \\
Gelatinous & 3.33 & $\mathbf{5 . 0 0 0}$ & $\mathbf{0}$ & 0.152 \\
zooplankton & & & & \\
Anchovy & 3.54 & $\mathbf{1 1 . 4 4 5}$ & $\mathbf{1 . 1 2 6}$ & 0.662 \\
Sardine & 2.99 & $\mathbf{5 . 3 8 1}$ & $\mathbf{1 . 1 6 5}$ & 0.743 \\
Redeye & 3.64 & $\mathbf{6 . 6 3 8}$ & $\mathbf{0 . 2 0 9}$ & 0.565 \\
Other small pelagic & 3.65 & $\mathbf{0 . 3 6 4}$ & $\mathbf{0 . 0 0 1}$ & 0.708 \\
fish & & & & \\
Chub mackerel & 3.82 & 0.138 & $\mathbf{0 . 0 0 2}$ & $\mathbf{0 . 9 0 0}$ \\
Juvenile horse & 3.63 & $\mathbf{0 . 2 9 8}$ & $\mathbf{0 . 0 1 5}$ & 0.552 \\
mackerel & & & & \\
Adult horse mackerel & 3.71 & $\mathbf{0 . 9 6 7}$ & $\mathbf{0 . 1 4 8}$ & 0.930 \\
Mesopelagic fish & 3.64 & 9.247 & $\mathbf{0 . 0 0 3}$ & $\mathbf{0 . 9 5 0}$ \\
Snoek & 4.37 & 0.272 & $\mathbf{0 . 0 4 2}$ & $\mathbf{0 . 9 5 0}$ \\
Other large pelagic & 4.54 & $\mathbf{0 . 1 0 6}$ & $\mathbf{0 . 0 3 2}$ & 0.882 \\
fish & & & & \\
Cephalopods & 4.08 & $\mathbf{1 . 7 7 3}$ & $\mathbf{0 . 0 4 1}$ & 0.712 \\
Small M. capensis & 3.95 & 0.533 & $\mathbf{0}$ & $\mathbf{0 . 9 5 0}$ \\
Large $M$. capensis & 4.64 & $\mathbf{0 . 6 5 3}$ & $\mathbf{0 . 1 3 0}$ & 0.869 \\
Small M. paradoxus & 3.87 & 1.907 & $\mathbf{0 . 0 4 5}$ & $\mathbf{0 . 9 5 0}$ \\
Large $M$. paradoxus & 4.52 & $\mathbf{0 . 9 5 9}$ & $\mathbf{0 . 4 7 4}$ & 0.859 \\
Pelagic-feeding & 3.98 & 3.877 & $\mathbf{0 . 0 3 7}$ & $\mathbf{0 . 9 5 0}$ \\
demersal fish & & & & \\
Benthic-feeding & 3.43 & 4.290 & $\mathbf{0 . 0 5 6}$ & $\mathbf{0 . 9 5 0}$ \\
demersal fish & & & & \\
Pelagic-feeding & 4.94 & $\mathbf{0 . 1 7 6}$ & $\mathbf{0 . 0 0 7}$ & 0.984 \\
chondrichthyans & & & & \\
Benthic-feeding & 3.7 & $\mathbf{1 . 2 1 0}$ & $\mathbf{0 . 0 0 2}$ & 0.754 \\
chondrichthyans & & & & \\
Apex & 5.08 & $\mathbf{0 . 0 4 2}$ & $\mathbf{0}$ & 0.001 \\
chondrichthyans & & & & \\
Seals & 4.67 & $\mathbf{0 . 1 3 3}$ & $\mathbf{0 . 0 0 3}$ & 0.399 \\
Cetaceans & 4.59 & $\mathbf{0 . 0 8 2}$ & $\mathbf{0}$ & 0.640 \\
Seabirds & 4.49 & $\mathbf{0 . 0 1 1}$ & $\mathbf{0}$ & 0 \\
Meiobenthos & 2 & 13.421 & $\mathbf{0}$ & $\mathbf{0 . 9 5 0}$ \\
Macrobenthos & 2.16 & 63.748 & $\mathbf{0}$ & $\mathbf{0 . 9 5 0}$ \\
Detritus & & - & $\mathbf{0}$ & 0.914 \\
\hline
\end{tabular}

tem (Table 3; for indicator formulae see Table S5 in Supplement 1).

Indicators need to effectively capture changes observed in the southern Benguela ecosystem without losing information through over-aggregation. Thus, the model-based indicators were examined for their ability to detect change within this ecosystem, and a sub-set was considered for use in decision trees to classify ecosystem trends largely in response to fishing. Table 3 provides the reasoning behind our indicator selection.
Table 2. Functional groups of the southern Benguela ecosystem used in the calculation of trophic indicators.

\begin{tabular}{|c|c|c|}
\hline $\begin{array}{l}\text { Functional } \\
\text { group }\end{array}$ & Code & $\begin{array}{l}\text { Individual } \\
\text { model groups }\end{array}$ \\
\hline $\begin{array}{l}\text { Pelagic-caught } \\
\text { fish }\end{array}$ & PEL & $\begin{array}{l}\text { Anchovy, sardine, redeye, other } \\
\text { small pelagic fish, juvenile } \\
\text { horse mackerel, chub mackerel, } \\
\text { mesopelagic fish, all large } \\
\text { pelagic fish (snoek and other } \\
\text { large pelagic fish such as kob, } \\
\text { yellowtail and tuna) }\end{array}$ \\
\hline $\begin{array}{l}\text { Demersal-caught } \\
\text { fish }\end{array}$ & DEM & $\begin{array}{l}\text { Adult horse mackerel, all hake } \\
\text { (small and large Merluccius } \\
\text { capensis and small and large } \\
\text { M. paradoxus), pelagic- and } \\
\text { benthic-feeding demersal fish }\end{array}$ \\
\hline Total fin fish & & $\begin{array}{l}\text { Pelagic-caught and demersal- } \\
\text { caught fish }\end{array}$ \\
\hline Small fish & SMF & $\begin{array}{l}\text { Anchovy, sardine, redeye, other } \\
\text { small pelagic fish, juvenile horse } \\
\text { mackerel, small hake }\end{array}$ \\
\hline Large fish & LAF & $\begin{array}{l}\text { Large hake, all large pelagic } \\
\text { fish (snoek and other large } \\
\text { pelagic fish) }\end{array}$ \\
\hline Planktivorous fish & PLA & $\begin{array}{l}\text { Anchovy, sardine, redeye, other } \\
\text { small pelagic fish, adult and } \\
\text { juvenile horse mackerel, } \\
\text { mesopelagic fish, small hake }\end{array}$ \\
\hline Piscivorous fish & PIS & $\begin{array}{l}\text { Chub mackerel, all large } \\
\text { pelagic fish (see above), large } \\
\text { hake, pelagic- and benthic- } \\
\text { feeding demersal fish }\end{array}$ \\
\hline $\begin{array}{l}\text { Pelagic fish } \\
\text { predators }\end{array}$ & PFP & $\begin{array}{l}\text { Chub mackerel, all large pe- } \\
\text { lagic fish (see above), large } \\
\text { hake, seals, cetaceans, seabirds }\end{array}$ \\
\hline Chondrichthyans & & $\begin{array}{l}\text { Apex, pelagic- and benthic- } \\
\text { feeding chondrichthyans }\end{array}$ \\
\hline
\end{tabular}

\section{Construction of decision trees}

The initial plan for classification of the southern Benguela ecosystem was to develop one decision tree that would combine the community and system indicators identified. However, it was difficult to separate the community and system indicators when a particular trend (system or community) needed to be clarified. Therefore 3 separate decision trees were developed: a pelagic-caught fish (PEL) community decision tree, a demersal-caught fish (DEM) community decision tree, and an ecosystem-level decision tree that used the 2 community-based trees.

Fish communities were largely separated according to fishery type, i.e. pelagic (purse-seine, line fishery, long line, other) and demersal (midwater trawl, demersal trawl, line fishery, long line, other). Although midwater trawl is a pelagic fishing gear, it 
난

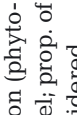

空

돌 :

臟

ه

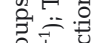

究息

बㄹ

नี च्च

들

究

क्

员芯点

考

品

蛋

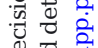

을

घै

总

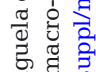

क्ष

宛家

है है है

on

a

空

형

递

ชิ

递

농

艺

औ

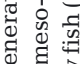

S

웡

氙

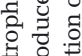

पै

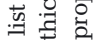

주웜

的

읨

중 $\frac{\pi}{2}$

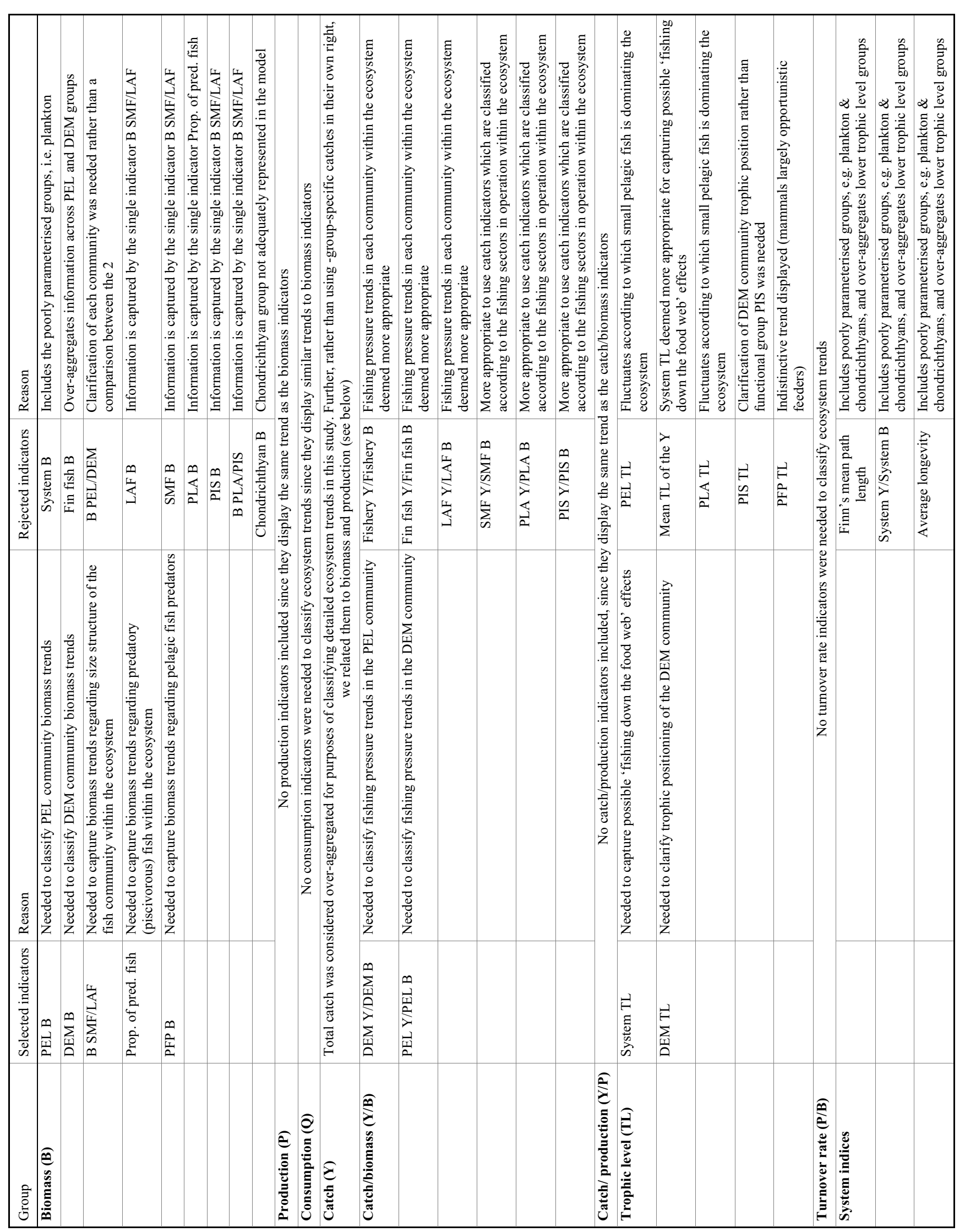


was included in the DEM classification because it targets adult horse mackerel, which are also caught within the demersal trawl fishery. Fish which are harvested within the PEL community are anchovy, sardine, redeye, other small pelagic fish, chub mackerel, juvenile horse mackerel, mesopelagic fish, snoek and other large pelagic fish. Fish harvested within the DEM community are adult horse mackerel, small and large shallow- and deep-water hake (respectively small Merluccius capensis, large $M$. capensis, small M. paradoxus, large M. paradoxus), pelagic- and benthic-feeding demersal fish. The 2 community indicators used in each community decision tree (Table 4) were biomass (B) and catch/biomass (Y/B), the latter so that catch could be assessed in relation to the biomass of the community in question, i.e. the combination of indicators is important in teasing out information on what is accounting for observed changes in the pelagic or demersal communities. The indicators were examined to determine whether they displayed 1 of 3 trends: Increase, Same or Decrease. Indicator trends were verified using an arbitrary $10 \%$ limit, i.e. $<10 \%$ change between the 2 time periods was classified as the same, whereas a $\geq 10 \%$ change between 2 (static) time periods was classified as an increasing/decreasing trend. Three classification trends were chosen for the endpoint of the community decision tree: Improving, Not improving or Deteriorating. Following Bundy et al. (2010), the general rule applied was that if one indicator displayed a trend in the wrong direction (e.g. B Decrease), and the other indicator did not compensate accordingly (e.g. Y/B Decrease), the community would receive a deteriorating classification.

If the assessments displayed by the PEL and DEM community were not the same (e.g. one was Improving, the other Not improving), a definitive ecosystem classification could not be reached, and ecosystem level clarification indicators were used for the component displaying the least positive trend. Carefully ordered indicator combinations were employed whereby ratio-based indicators (such as proportion of predatory fish and the ratio of small to large fish) are used in logical sequences to complement simpler, more directly estimated indicators, in an effort to identify the main reasons for the observed community and ecosystem changes over time. The trends for the indicators used in the community decision trees were also used in the ecosystem decision tree, i.e. Increase, Same or Decrease; and the $10 \%$ limit was also employed. However, 4 classification trends were used for the end point of the ecosystem decision tree: Improving, Not improving, Deteriorating or Can't say. The classification 'Can't say' was included in the ecosystem decision tree because more indicators are used, which could result in contradictory trends, no trends or difficulty distinguishing between 2 ecosystem classifications.

The decision trees developed were applied to check that the decision tree logic was sound, consistent and robust. Here, 5 time periods were tested: the 1900s, 1960s, 1980s, 1990s and 2004-2008. The data needed to calculate the indicators for previous time periods were sourced from Shannon et al. (2003) (1980s and 1990s trophic model), and Watermeyer et al. (2008) (1900s and 1960s trophic model). Comparisons were made between 2 sequential periods, i.e. 1960s compared to 1900 s, 1980 s compared to 1960 s, 1990s compared to 1980s and 2004-2008 compared to 1990s. An additional comparison was made between the 2004-2008 and 1980s periods, because both these time periods were modelled as anchovydominated and thus it would be of interest to note any ecosystem changes.

\section{RESULTS}

\section{Comparing model-derived indicators across time periods}

Biomass of the entire southern Benguela ecosystem (total system B), excluding detritus, was at its highest value for the 2004-2008 period, with an overall increase of $23 \%$ from the 'pristine' to the 2004-2008 period (Fig. 2). Functional groups displaying maximum biomass values during the 2000s were total fin fish, total pelagic-caught (PEL), total small fish (SMF) and total planktivorous fish (PLA). Survey-estimated biomasses (model inputs) of small pelagic fish and cephalopods were higher in the period 2004-2008 than previously, and model-estimated biomasses of both pelagic- and benthic-feeding demersal fish increased from the 1980s onwards. Model-estimated biomass (model outputs) of Cape hake in the 1900s was $7.2 \mathrm{t} \mathrm{km}^{-2}$, whereas in 2004-2008, modelled hake biomass was $4.1 \mathrm{t} \mathrm{km}^{-2}$. The 2004-2008 modelestimated biomass for small Merluccius capensis is less than half of the estimated value for small $M$. paradoxus (Table 1), whereas survey-estimated biomass for large $M$. paradoxus is higher than for $M$. capensis. The higher survey-estimated $M$. paradoxus biomass compared to that of $M$. capensis observed in 2004-2008 was also observed during the 1900s and 1960s (Watermeyer et al. 2008). The proportion of hake production removed through predation/canni- 
Table 4. Rules and explanations for the decisions reached within the pelagic-caught fish (PEL) and demersal-caught fish $(\mathrm{DEM})$ community decision trees. incr = increase; decr = decrease. Not improving $=$ the community in question can sustain the current fishing pressure. Possible changing environmental conditions or fishing practices can negatively affect this community. Improving $=$ the biomass of the community in question is increasing and this community can sustain the current fishing pressure. Possible changing environmental conditions or fishing practices can negatively affect this community. Deteriorating = the current fishing pressure is too high to be sustained by the community in question (see Tables $2 \& 3$ for further abbreviations)

\begin{tabular}{|c|c|c|}
\hline Rule no. & Indicator (Trend) & Decision \\
\hline \multicolumn{3}{|l|}{ PEL } \\
\hline 1 & $\begin{array}{l}\text { PEL B (incr) } \\
\text { PEL Y/B (incr) }\end{array}$ & Not improving \\
\hline 2 & $\begin{array}{c}\text { PEL B (incr) } \\
\text { PEL Y/B (same/decr) }\end{array}$ & Improving \\
\hline 3 & $\begin{array}{c}\text { PEL B (same) } \\
\text { PEL Y/B (incr/same/decr) }\end{array}$ & Not improving \\
\hline 4 & $\begin{array}{c}\text { PEL B (decr) } \\
\text { PEL Y/B (incr/same/decr) }\end{array}$ & Deteriorating \\
\hline 5 & $\begin{array}{l}\text { PEL B (decr) } \\
\text { PEL Y/B (decr) }\end{array}$ & Not improving \\
\hline \multicolumn{3}{|l|}{ DEM } \\
\hline 1 & $\begin{array}{l}\text { DEM B (incr) } \\
\text { DEM Y/B (incr) }\end{array}$ & Not improving \\
\hline 2 & $\begin{array}{c}\text { DEM B (incr) } \\
\text { DEM Y/B (same/decr) }\end{array}$ & Improving \\
\hline 3 & $\begin{array}{c}\text { DEM B (same) } \\
\text { DEM Y/B (incr/same/decr) }\end{array}$ & Not improving \\
\hline 4 & $\begin{array}{c}\text { DEM B (decr) } \\
\text { DEM Y/B (incr/same/decr) }\end{array}$ & Deteriorating \\
\hline 5 & $\begin{array}{l}\text { DEM B (decr) } \\
\text { DEM Y/B (decr) }\end{array}$ & Not improving \\
\hline
\end{tabular}

balism by $M$. paradoxus and $M$. capensis is estimated to have decreased since the 1900s; consumption of hake by $M$. paradoxus showed a larger overall decline than that of $M$. capensis (65 vs. $59 \%$ respectively).

Four functional groups displayed a decrease in biomass from the 1900s to the 2000s: total DEM, total large fish (LAF), total piscivorours fish (PIS) and total pelagic fish predators (PFP) (Fig. 2). Total chondrichthyan biomass underwent a significant decline between 1900 and 1960, peaked in the 1980s and has remained relatively stable since (Fig. 2 d). Total fin fish biomass was highest in the 2000s, dominated by the functional groups PEL, SMF and PLA. On average, the groups PEL, SMF and PLA represent 68, 50 and $77 \%$ of the total fin fish biomass in the southern Benguela ecosystem over the 4 time periods examined.

Only one of the 4 biomass indicator ratios calculated, B small fish/B large fish (SMF/LAF) showed a consistent increasing pattern over time (Fig. 2e). Biomass of all pelagic-caught fish:demersal-caught fish (PEL/DEM) and biomass of planktivorous fish:pisci- vorous fish (PLA/PIS) were higher in 2004-2008 than in 1900, whereas the proportion of predatory fish (prop. of pred. fish) was lower in 2004-2008 than in 1900.

Trends in production and consumption indicators - which are outputs of the models, based on input parameters (see Table 1 \& Table S1 in Supplement 1, for model input versus model output parameters) - corresponded to biomass trends discussed above and were thus omitted both for plotting and decision tree purposes, since they provided little additional information above that summarised in the biomass-based indicators.

Maximum catches (inputs to the model) were recorded during the 2004-2008 period for the groups: total system, total fin fish, PEL, SMF and PLA (Fig. 3a,b). Catch of DEM, LAF and PIS declined between the 1960s and the 1980s. PEL/DEM, SMF/ LAF and PLA/PIS were all highest in the 2000s (Fig. 3c). The summed catches of the target species of the small pelagic fishery, namely anchovy, sardine and redeye, increased since the $1960 \mathrm{~s}$, peaking in the 2004-2008 period. Catches of snoek and other large pelagic fish combined increased 3-fold between 1900 and 1960 (to $0.075 \mathrm{t} \mathrm{km}^{-2} \mathrm{yr}^{-1}$ ). Since the 1960s, catches of large pelagic fish have remained constant. Cephalopod catch increased by a factor of 1.5 from 1980 to the 2000s (Osman 2010). Catches for the 2 hake species underwent opposite trends between 1980 and 2004-2008. M. capensis catch halved whereas $M$. paradoxus catch increased by $36 \%$. Chondrichthyan catch underwent a large increase between 1960 and 1980, declining again thereafter. Seals were harvested in the Benguela ecosystem, starting in the 17th century (Rand 1952, 1972). Control measures on sealing were introduced in the early 20th century (Kirkman 2010). Targeted harvesting of both seals and cetaceans have ceased in recent decades in the southern Benguela ecosystem, with only incidental mortalities of seals caught in fishing gear (Table S2 in Supplement 1).

TL (model output) of the catch (Y), system (excluding plankton, benthos and detritus) and all functional groups (PEL, DEM, PLA, PIS, PFP) all decreased relative to that calculated for the 1900s (Fig. 4). TL of Y, system, DEM and PIS groups were lowest in the 2000s. All aggregated model groups except LAF showed a decline in catch/biomass (Y/B) between the 1980s and the 2000s (Fig. 5). Y/B of 5 of the 8 groups peaked in the 1980 s. Catch/production indicators (not shown) exhibited the same trends as Y/B indicators. Catch/production and Y/B are merely 2 viewpoints of the same system. The catch/production indicator is more tangible to ecosystem scientists who 


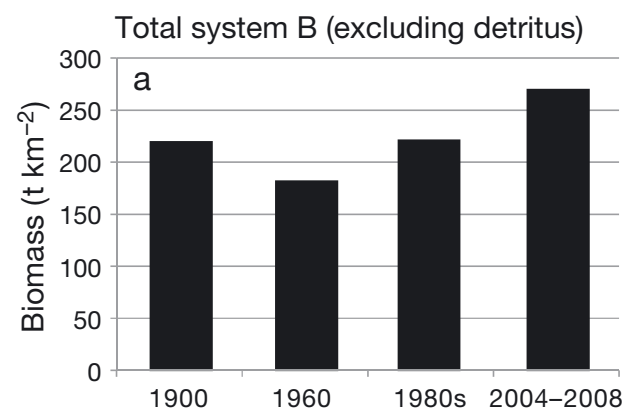

SMF, PLA, and PIS B
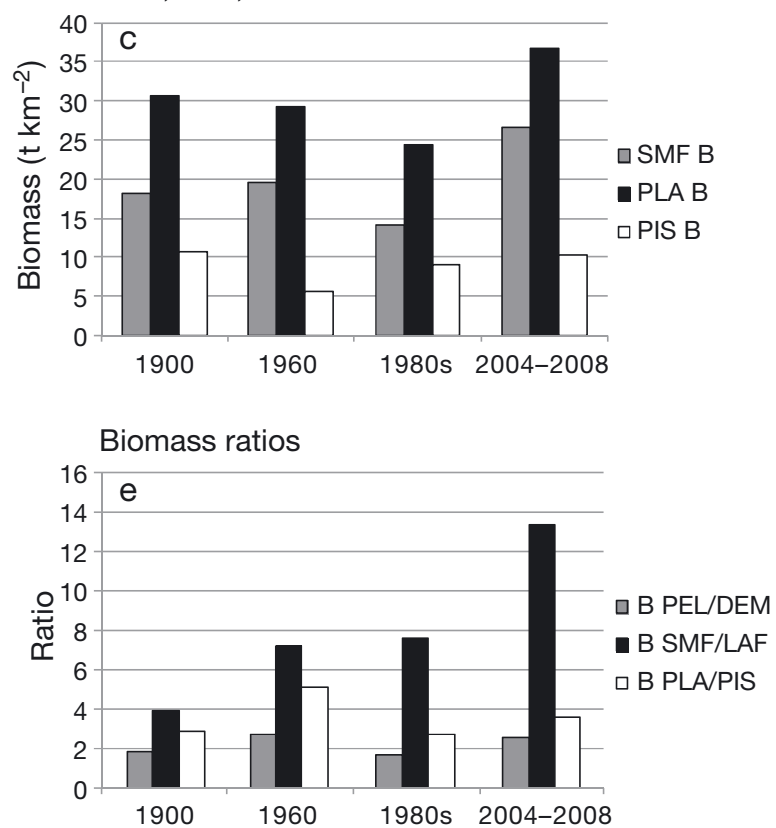
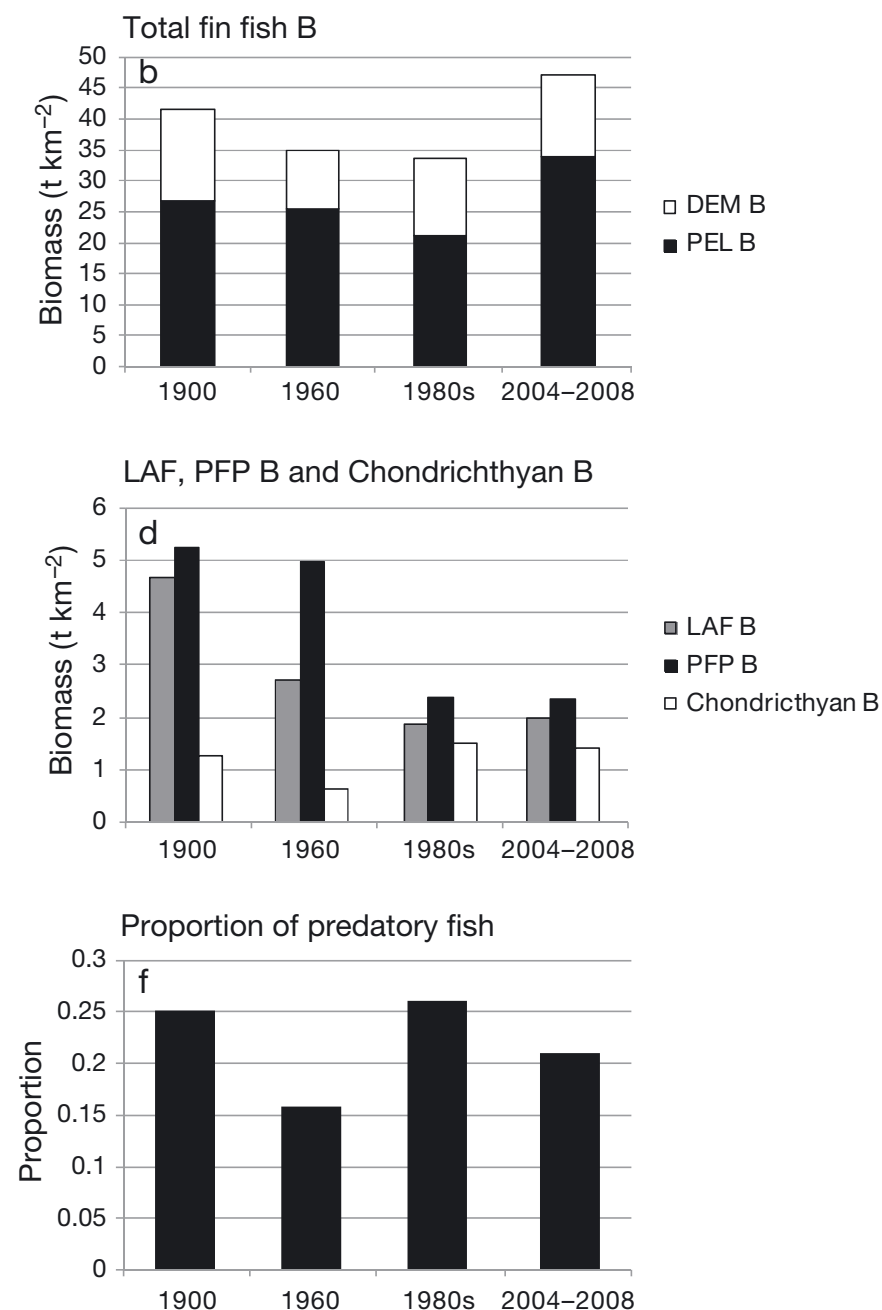

Fig. 2. Biomass (B) indicators of the southern Benguela ecosystem over the time periods 1900, 1960, 1980 and $2004-2008$. Data for 1980 to 1989 were sourced from Shannon et al. (2003) and for 1900 and 1960 from Watermeyer et al. (2008). See Table 2 for species included in functional groups plotted

wish to understand the dynamics of the ecosystem, whereas Y/B is likely to be more tangible to fisheries managers who are more concerned with harvesting levels, i.e. relative to biomass.

All fish groups except DEM P/DEM B and PIS P/PIS B experienced declines in their turnover rate from the 1900s (Fig. 6). The DEM turnover rate peaked in the 1960s. Turnover rate for the group PIS was higher in the 1980s and 2000s than in earlier periods.

\section{Decision trees}

A flow diagram of the PEL and DEM community decision trees is displayed in Fig. 7. A total of 5 rules were used to arrive at 9 possible outcomes. Explanations for each rule for each community decision tree are provided in Table 4 . There were 5 cases of Not improving and 2 cases each of Improving and Deteriorating, for both community decision trees.

The entire flow diagram for the southern Benguela ecosystem decision tree can be viewed in Fig. 8. The 3 branches of the decision tree (Improving PEL community branch, Not improving PEL community branch, Deteriorating PEL community branch) are also displayed for clarity (Fig. 9). The ecosystem decision tree displayed 40 possible outcomes after evaluating 29 rules (Table 5). There were 2 cases of Improving, 15 cases of Not improving, 13 cases of Deteriorating and 10 cases of Can't say.

Pair-wise comparisons of the state of the southern Benguela ecosystem using the decisions trees are displayed in Table 6. Three different decision outcomes were found in the history of the southern Benguela ecosystem: one Deteriorating (1960s vs. 

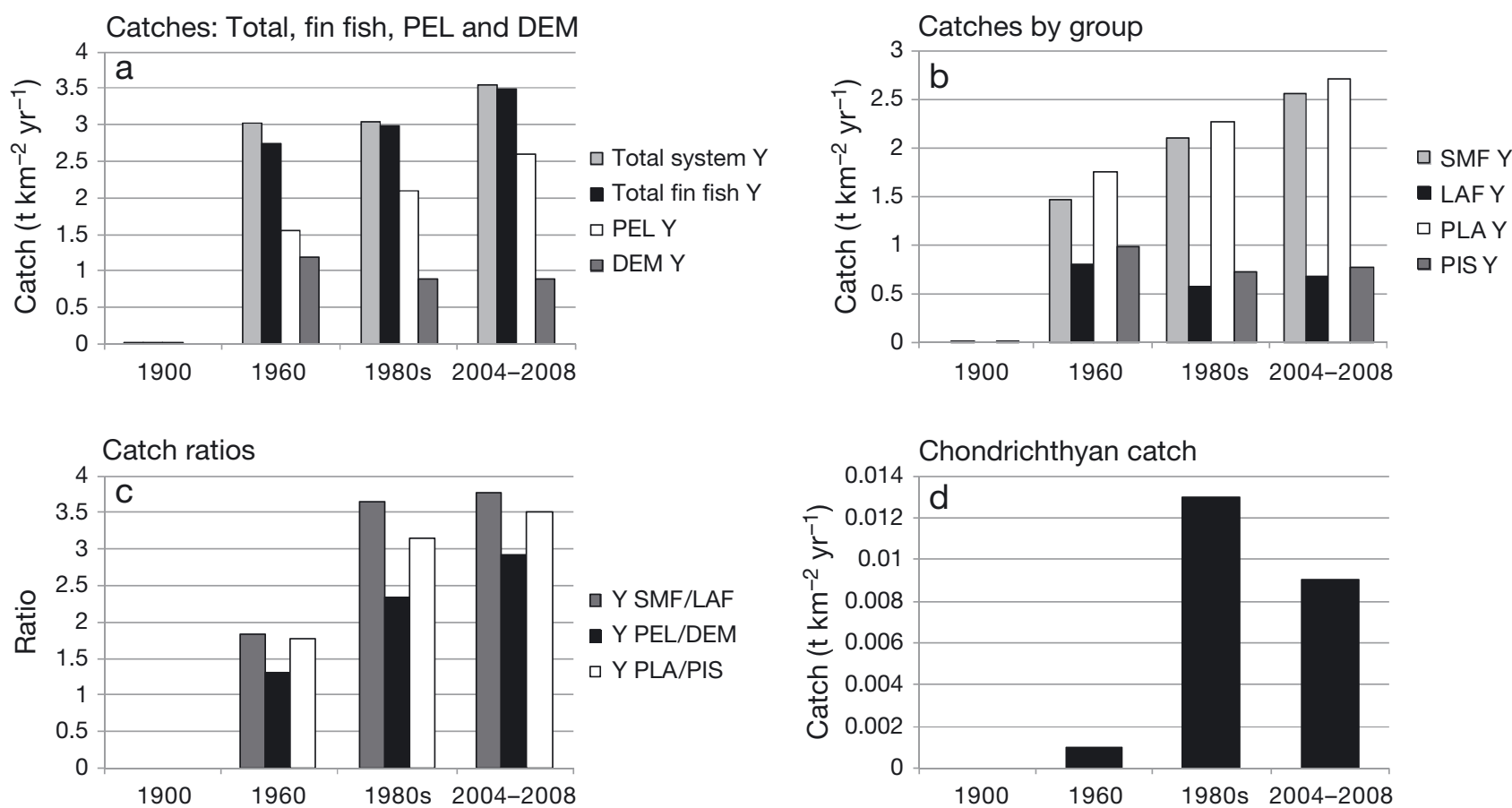

Fig. 3. Catch (Y) indicators of the southern Benguela ecosystem over the time periods 1900, 1960, 1980 and 2004-2008. Data for 1980 to 1989 were sourced from Shannon et al. (2003) and for 1900 and 1960 from Watermeyer et al. (2008). See Table 2 for species included in functional groups plotted

1900 s) and 3 cases of Not improving (1980s vs. 1960s, 1990 s vs. 1980 s, and $2004-2008$ vs. 1980 s) and one case where no definitive assessment could be made (2004-2008 vs. 1990s) (Table 6). For simplicity, only these 5 observations are shown in the table. To link these changes back to the indicator values reported in the present study, the relative change in the relevant indicators considered in the decision trees is provided for the 5 respective pairwise comparisons (Fig. 10). A working example of how the decision trees were used is provided for the 1990s vs 1980s comparison using changes in indicators calculated from data presented in Shannon et al. (2003) for these 2 model periods (Supplement 2, www.int-res.com/ articles/suppl/m512p217_supp.pdf).

\section{DISCUSSION}

\section{Changes in the southern Benguela ecosystem food web inferred from model-generated indicators}

Changes in functional group ratios can be related to changes within communities, which translate into changes in ecosystem functioning (Cury et al. 2005). Catch ratios (model inputs) and the mean TL (model output) of the catch are expected to capture potential 'fishing down the food web' (Pauly et al. 1998) effects as a result of the removal of large, predatory, high TL fish from the system, which has also taken place in the southern Benguela ecosystem (Shannon et al. 2009a). The indicator 'proportion of predatory fish' is a measure of fish diversity and can reflect effects of fishing on ecosystem functioning (Shin et al. 2010).

\section{Biomass-based indicators}

Biomass-based indicators rely on a mix of model input and model-estimated values (see Table 1 and Table S1 in Supplement 1). Although the PEL functional group includes all large pelagic fish (snoek and other large pelagic fish), this group represents $<2 \%$ of the total functional group biomass during all 4 time periods. The remaining $98 \%$ comprise small pelagic fish (anchovy, sardine, redeye, other small pelagic fish, juvenile horse mackerel, mesopelagic fish) and chub mackerel. Given the eastward shift in several marine resources, more anchovy and sardine are now located off the south coast of South Africa (Fig. 1). Following this shift in distribution, changes within the ecosystem food web can be expected. For example, historic field studies of estimated cephalopod diet report the frequency of occurrence of small pelagic fish within the diet from low to variable (Lipinski 1992). The assumption underlying the 2000s 

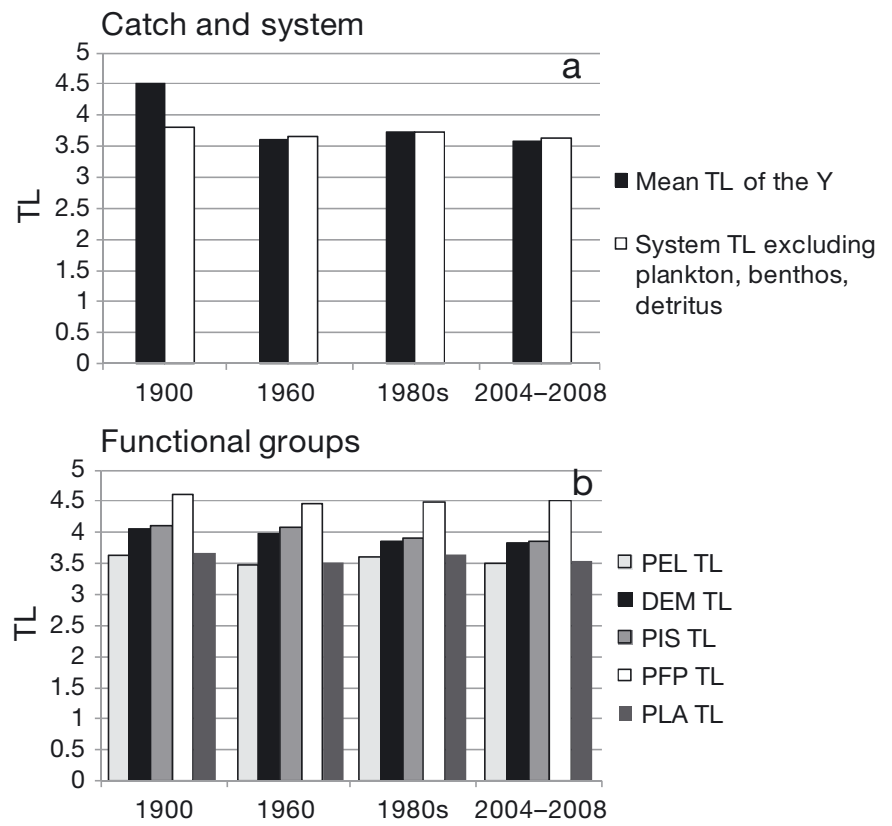

Fig. 4. Trophic level (TL) of the total catch (Y) and of functional groups in the southern Benguela ecosystem over the time periods 1900, 1960, 1980 and 2004-2008. Data for 1980 to 1989 were sourced from Shannon et al. (2003) and for 1900 and 1960 from Watermeyer et al. (2008). System = all model groups except phytoplankton, benthic producers, micro-, meso-, macro- and gelatinous zooplankton, meioand macrobenthos, and detritus. See Table 2 for species included in functional groups plotted

model is that cephalopod consumption of small pelagic fish may have increased 2-fold due to higher predator-prey encounter rates.

Model biomass of PIS increased from the 1960s. Model biomass of benthic-feeding demersal fish is estimated to have increased by $22 \%$ between 1980 and 2004-2008. These modelled increases, required to sustain predation and catches in the southern Benguela ecosystem, are supported by research survey biomass indices that were available at the time for a selection of key species (Department of Agriculture, Forestry and Fisheries [DAFF] unpubl. data).

Total LAF biomass declined over time (Fig. 2d). Yemane et al. (2004) found a decrease in size structure and abundance of large pelagic fish within the Cape region, attributed to overfishing (Griffiths 2000, Yemane et al. 2004). Yemane et al. (2004) also documented a change in the catch composition of large pelagic fish, with snoek being the dominant species caught. Griffiths (2000) identified the migratory lifestyle and fast growth-rates of snoek as the overriding factors preventing an exponential decline in the snoek stock. Large pelagic fish, like carpenter, geelbek and hottentot, have predictable locations
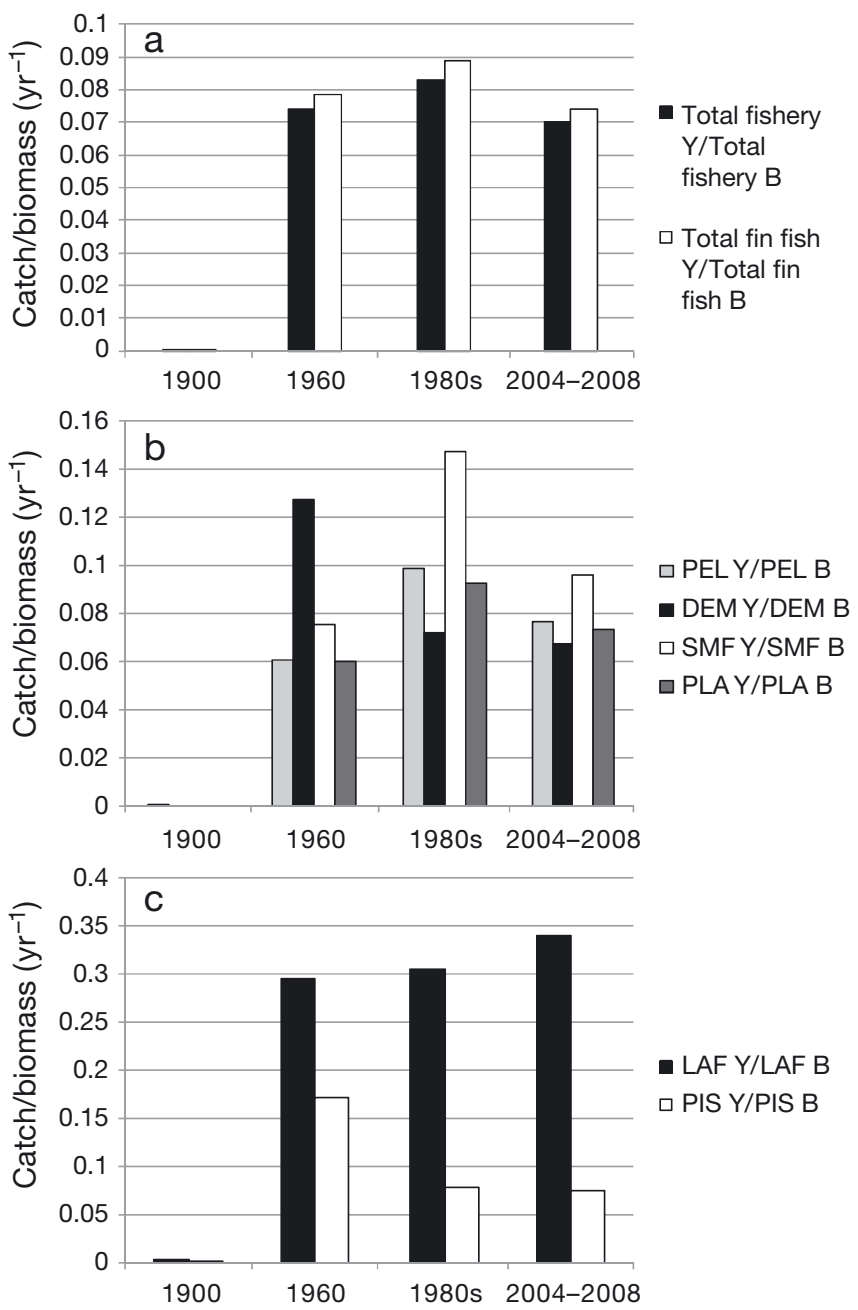

Fig. 5. Catch/biomass (Y/B) indicators of the southern Benguela ecosystem over the time periods 1900, 1960, 1980 and 2004-2008. Data for 1980 to 1989 were sourced from Shannon et al. (2003) and for 1900 and 1960 from Watermeyer et al. (2008). Total fishery = fin fish, cephalopods and chondrichthyans (apex, pelagic- and benthic-feeding) caught. See Table 2 for species included in functional groups plotted

in time and space as well as slow growth rates, making them more susceptible to stock declines or crashes because they are easier to target and catch (Griffiths 2000). Further, their production is not sufficiently high to support the commercial fishery (Griffiths 2000). This is evident in the reduced surveyestimated biomass observed for the 'Other large pelagic fish' model group, since the 1980s.

Chondrichthyans and demersal fish feeding patterns are not ideally represented within the series of comparable trophic models for the southern Benguela ecosystem, developed to focus on the pelagic, mid-trophic level components of the ecosystem. As is the case with zooplankton, a dedicated benthic/dem- 

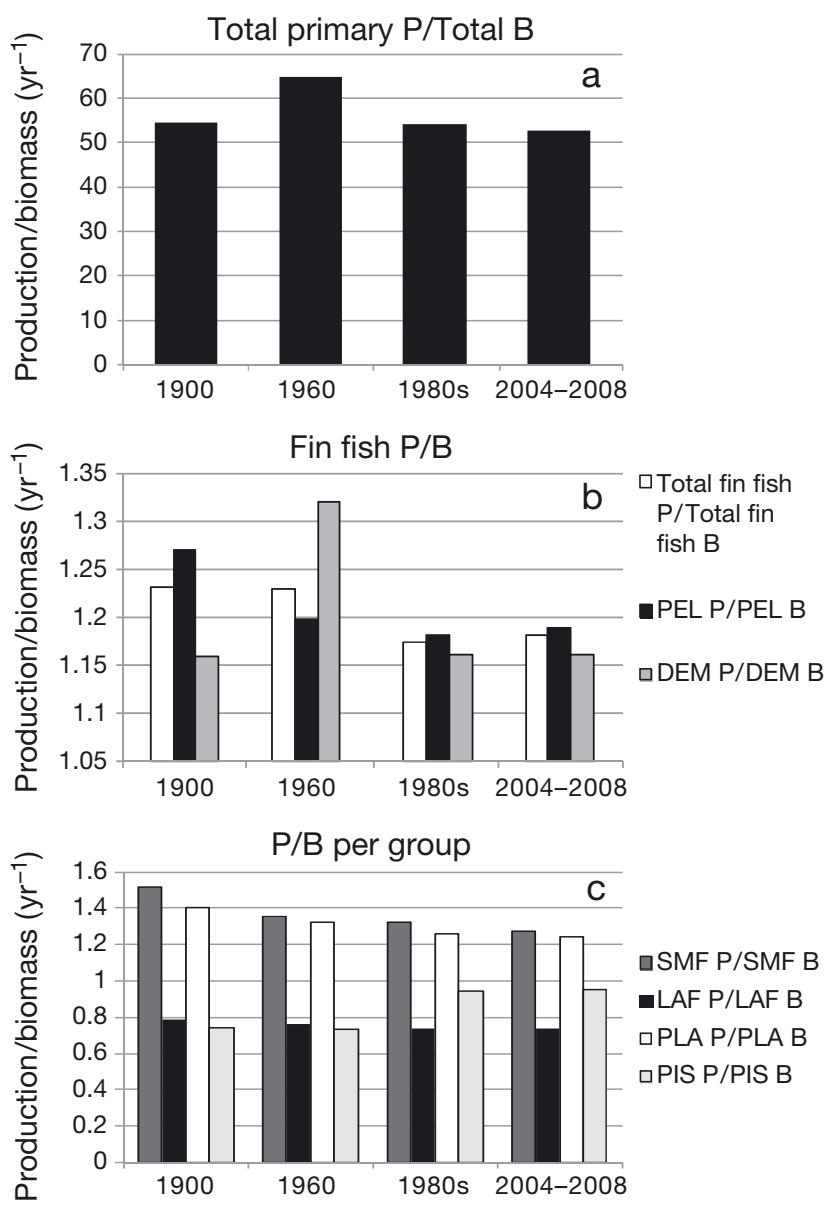

Fig. 6. Production (P)/biomass (B) turnover rate indicators of the southern Benguela ecosystem over the time periods $1900,1960,1980$ and 2004-2008. Data for 1980 to 1989 were sourced from Shannon et al. (2003) and for 1900 and 1960 from Watermeyer et al. (2008). See Table 2 for species included in functional groups plotted

ersal model needs to be constructed if a more accurate depiction of the feeding patterns of chondrichthyans and demersal fish is required.

The increase in small, planktivorous fish and decrease in large, predatory/piscivorous fish is captured in the biomass ratios: SMF/LAF, PEL/DEM and PLA/PIS, which all increased over time, also reflected in the decline in proportion of predatory fish.

Cephalopod biomass increased between the 1980s and 2004-2008 (DAFF unpubl. data), in line with similar increases observed in other ecosystems around the world (Caddy \& Rodhouse 1998). This increase in biomass elsewhere is thought to be in response to the declining biomass of groundfish species as a result of overfishing (Caddy \& Rodhouse 1998), thus releasing cephalopods from the potentially limiting predator-prey interactions with ground- fish species. Similarly, the increased abundance of cephalopods has corresponded with a decline in demersal fish abundance in the southern Benguela ecosystem.

Cephalopods are an important trophic link in the southern Benguela ecosystem. They are opportunistic predators that feed on a wide variety of prey items including macrozooplankton, anchovy, lightfish, lanternfish and hake, and are important prey items of various fish species, accounting for temporally and spatially variable portions of the diet of the 2 species of Cape hake, in particular (Lipinski et al. 1992).

\section{Catch-based indicators (model input)}

Fishing sectors in the southern Benguela ecosystem have shifted towards small, pelagic and planktivorous fish which occur lower in the food web. The catches of PEL, SMF and PLA have all increased over time, and in the 2004-2008 period, they represent 74, 73 and $78 \%$ of the total fish biomass removed from the system by the various fishing sectors. Catches of DEM, LAF and PIS have decreased since the 1960s. However, the catch ratio SMF/LAF increased between 1960 and the 1980s, reflecting the increase in SMF catch, but showed little change since the 1980s given increases in catches of both SMF and LAF between the 1980s and the 2000s. The catch ratios PEL/DEM and PLA/PIS display increasing trends over time, reinforcing the observed increases in fisheries based on pelagic and planktivorous fish.

\section{Trophic level indicators (model output)}

DEM and PIS functional groups displayed a consistent decrease in trophic level over time. Within DEM, the highest biomass contributor is benthic-feeding demersal fish, having the lowest TL. More substantial (greater spatial and species coverage) and more recent studies of the higher trophic level groups would strengthen model outputs with regard to the calculation of trophic levels. The declining TL of PIS can be attributed to (1) the increase in the lower TL benthic- and pelagic-feeding demersal fish abundance as estimated by the model; $(2)$ the reduced large hake biomass since the 1980s (pre-1980: $>2.4 \mathrm{t}$ $\mathrm{km}^{-2}$ vs. post-1980: $<1.6 \mathrm{t} \mathrm{km}^{-2}$ ) and (3) the increase in consumption of sardine by large hake between the 1980s and current period $\left(1980=0 \mathrm{t} \mathrm{km}^{-2} \mathrm{yr}^{-1} \mathrm{vs}\right.$. $\left.2004-2008=0.195 \mathrm{t} \mathrm{km}^{-2} \mathrm{yr}^{-1}\right)$. The fluctuating TL of PEL and PLA are a result of the alternating abun- 


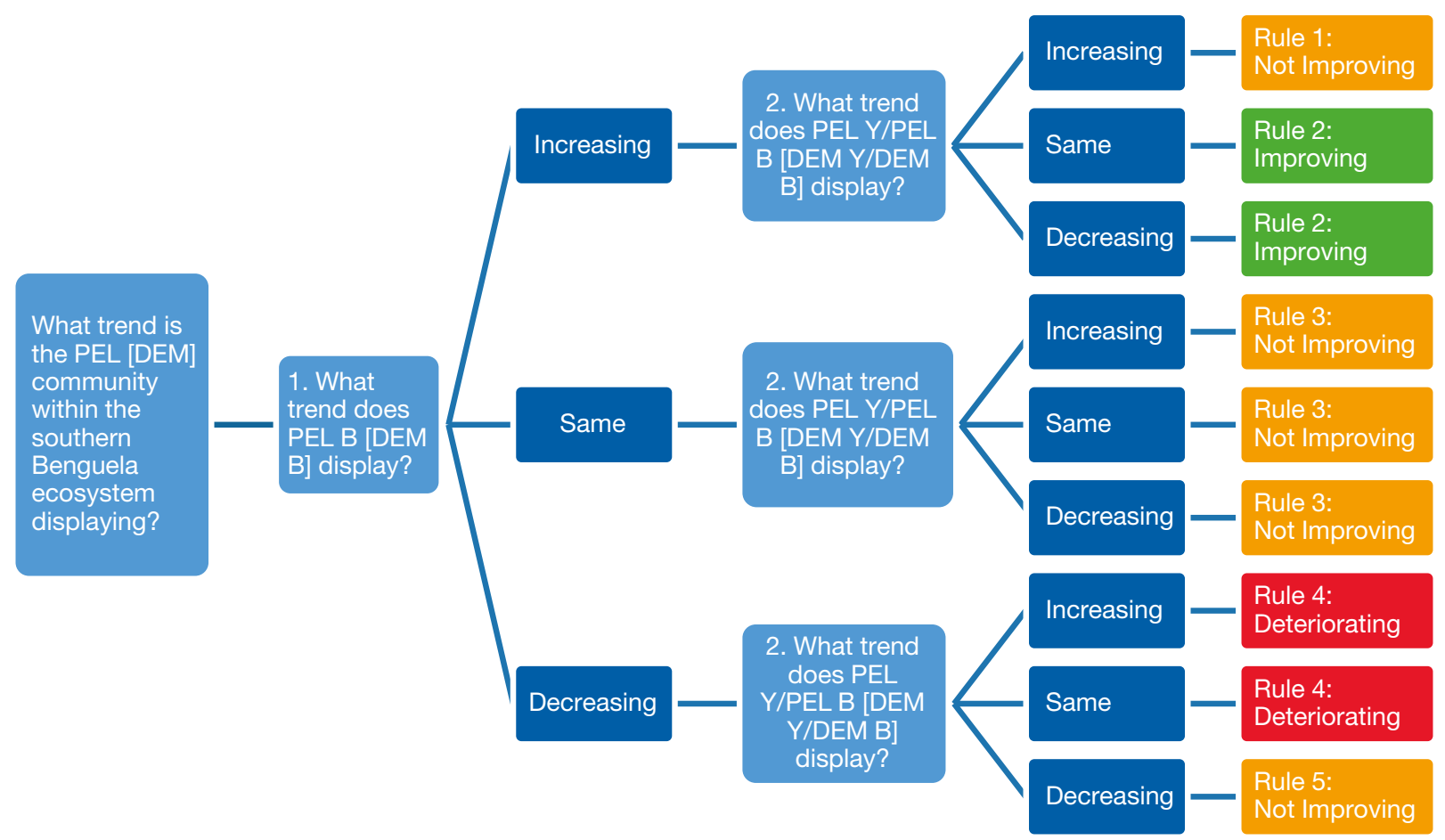

Fig. 7. Pelagic-caught fish (PEL) community decision tree for the southern Benguela ecosystem. $\mathrm{B}=\mathrm{biomass}\left(\mathrm{t} \mathrm{km}{ }^{-2}\right), \mathrm{Y}=\mathrm{catch}$ $\left(\mathrm{t} \mathrm{km}^{-2} \mathrm{yr}^{-1}\right)$. Similarly, to assess the demersal-caught fish community, PEL may be substituted for DEM (see square brackets).

See Table 2 for other abbreviations

Key:
\begin{tabular}{|c|}
\hline Improving \\
\hline Not Improving \\
\hline Deteriorating \\
\hline $\begin{array}{c}\text { Indicator Trend } \\
\text { Displayed }\end{array}$ \\
\hline$\uparrow$ (Increase) \\
\hline$=$ (Same) \\
\hline$\downarrow$ (Decrease) \\
\hline
\end{tabular}
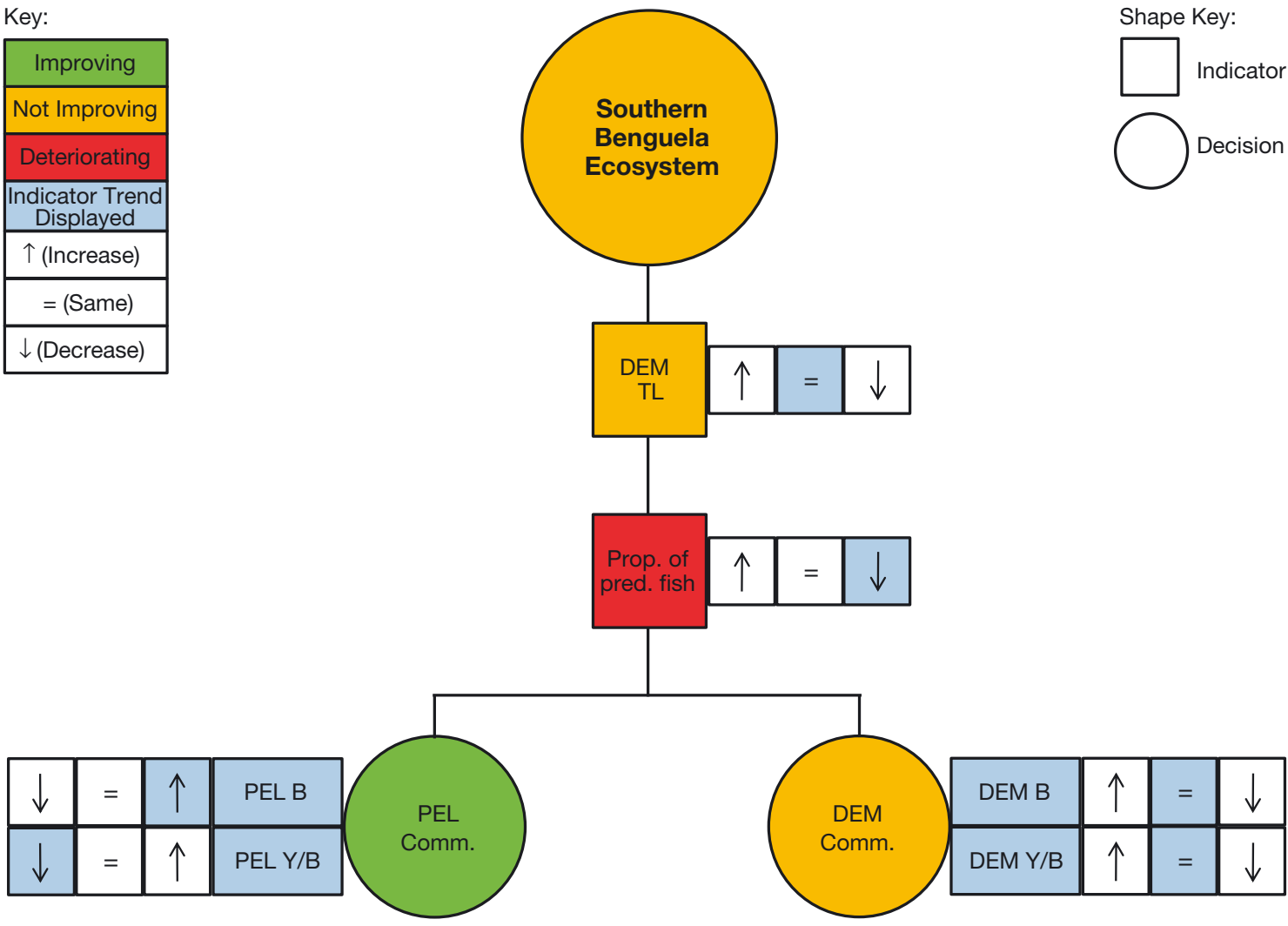

Fig. 8. Visual representation of the 2004-2008 vs. 1980s trends displayed by the southern Benguela ecosystem when using the pelagic-caught fish (PEL) community decision tree, the demersal-caught fish (DEM) community decision tree and the southern Benguela ecosystem decision tree and their associated indicators. Comm. = community; $\mathrm{B}=\mathrm{biomass} ; \mathrm{Y} / \mathrm{B}=\mathrm{catch} /$ biomass; Prop. of pred. fish = proportion of predatory fish; $\mathrm{TL}=$ trophic level. See Table 2 for other abbreviations 


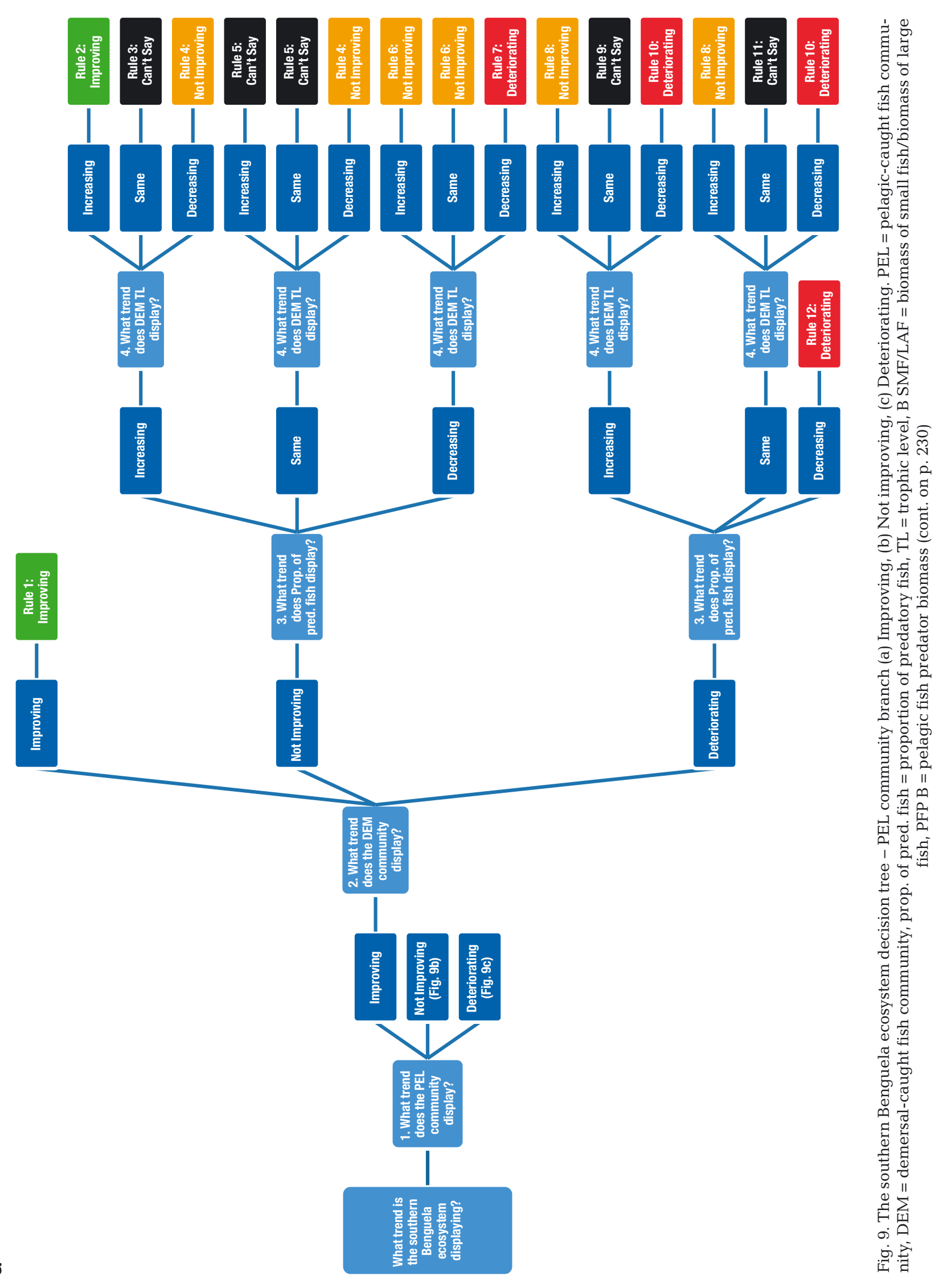



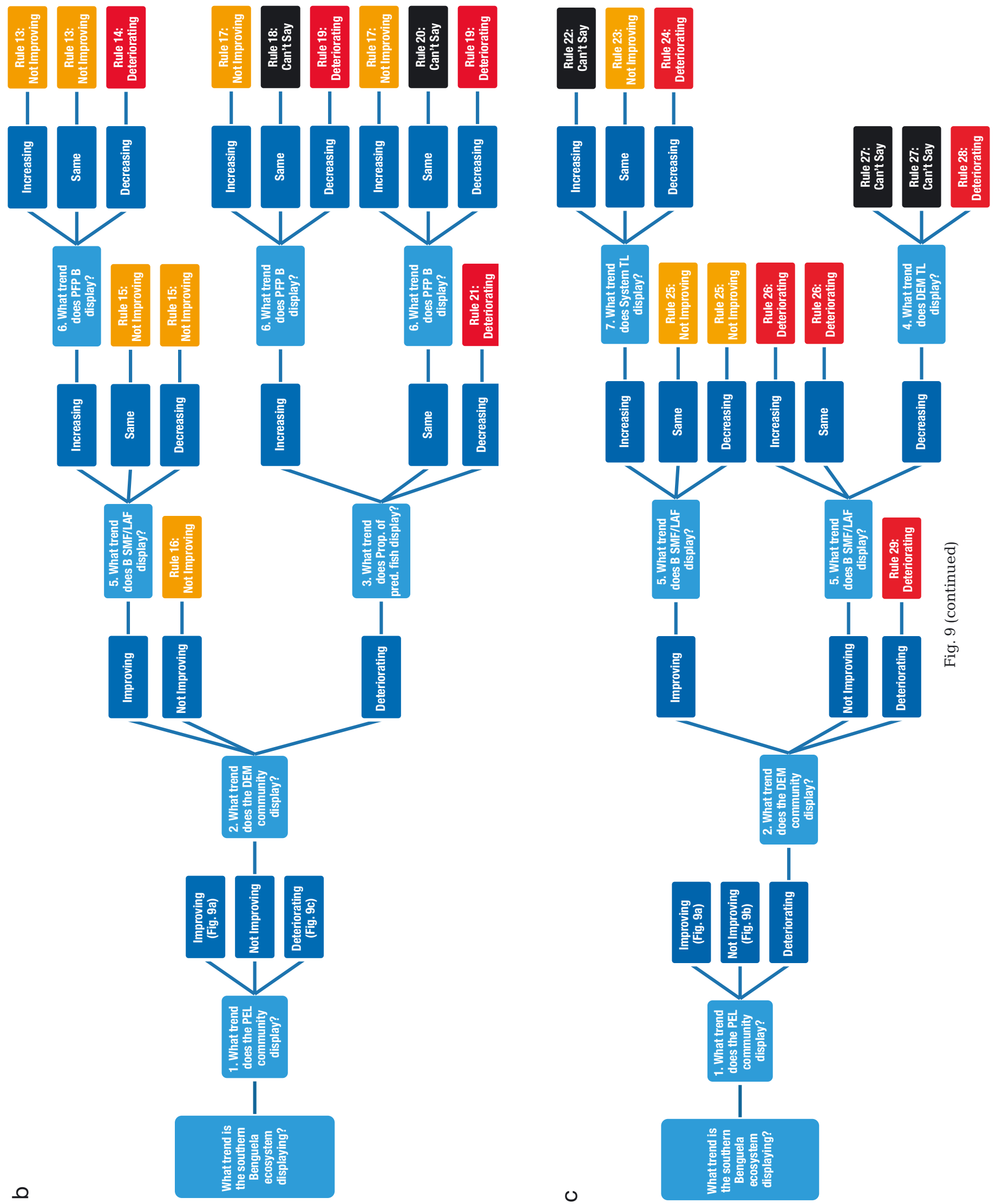


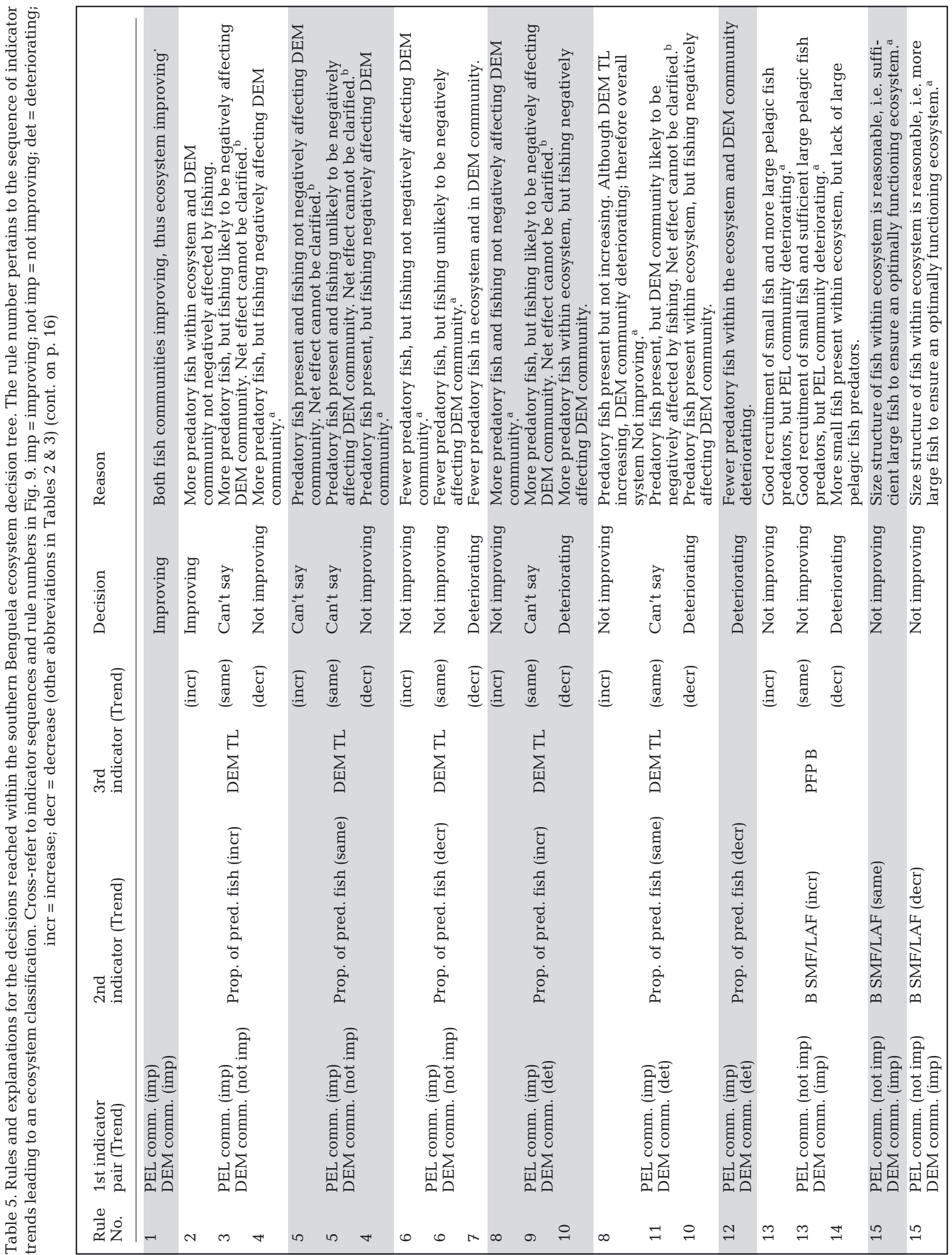




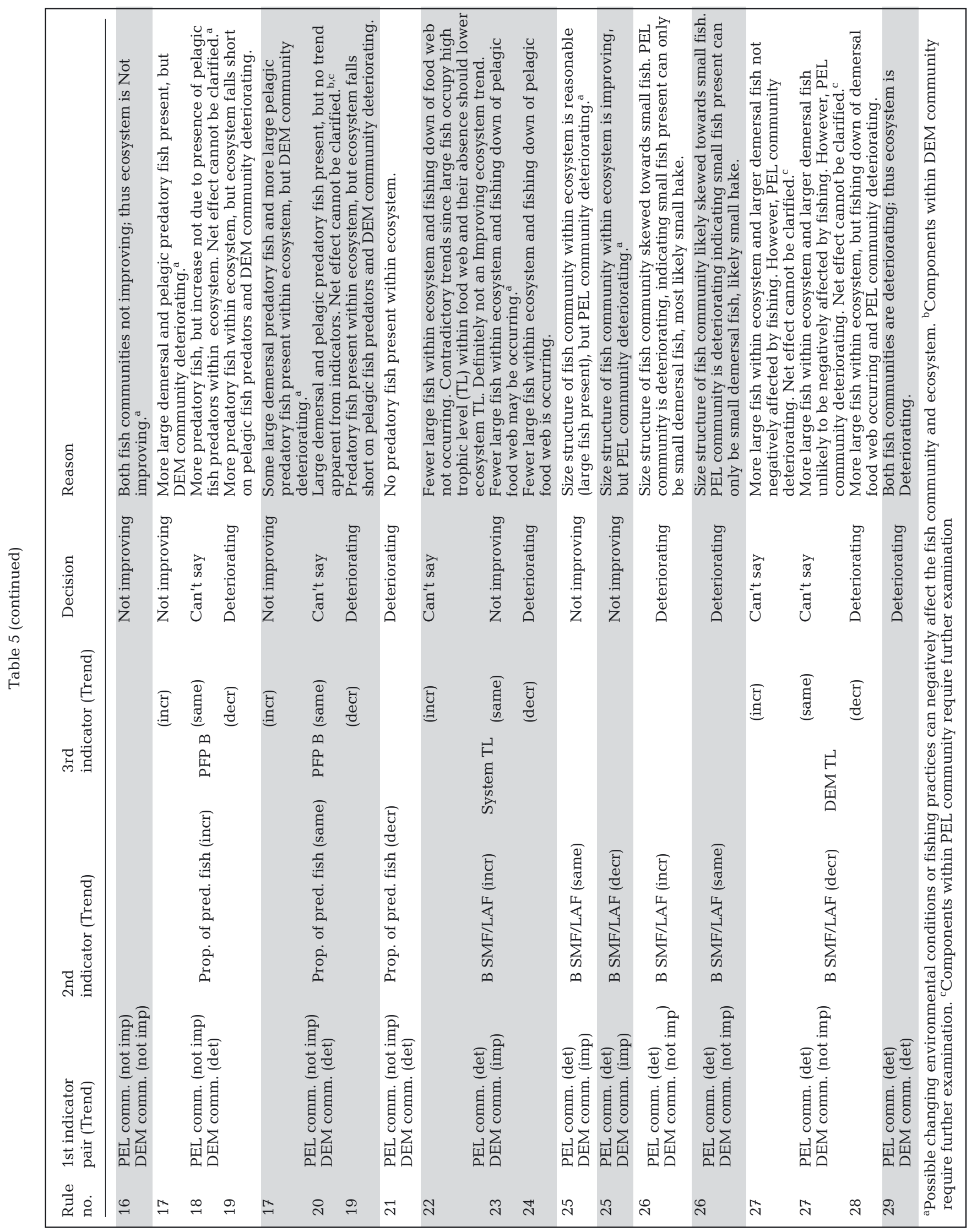




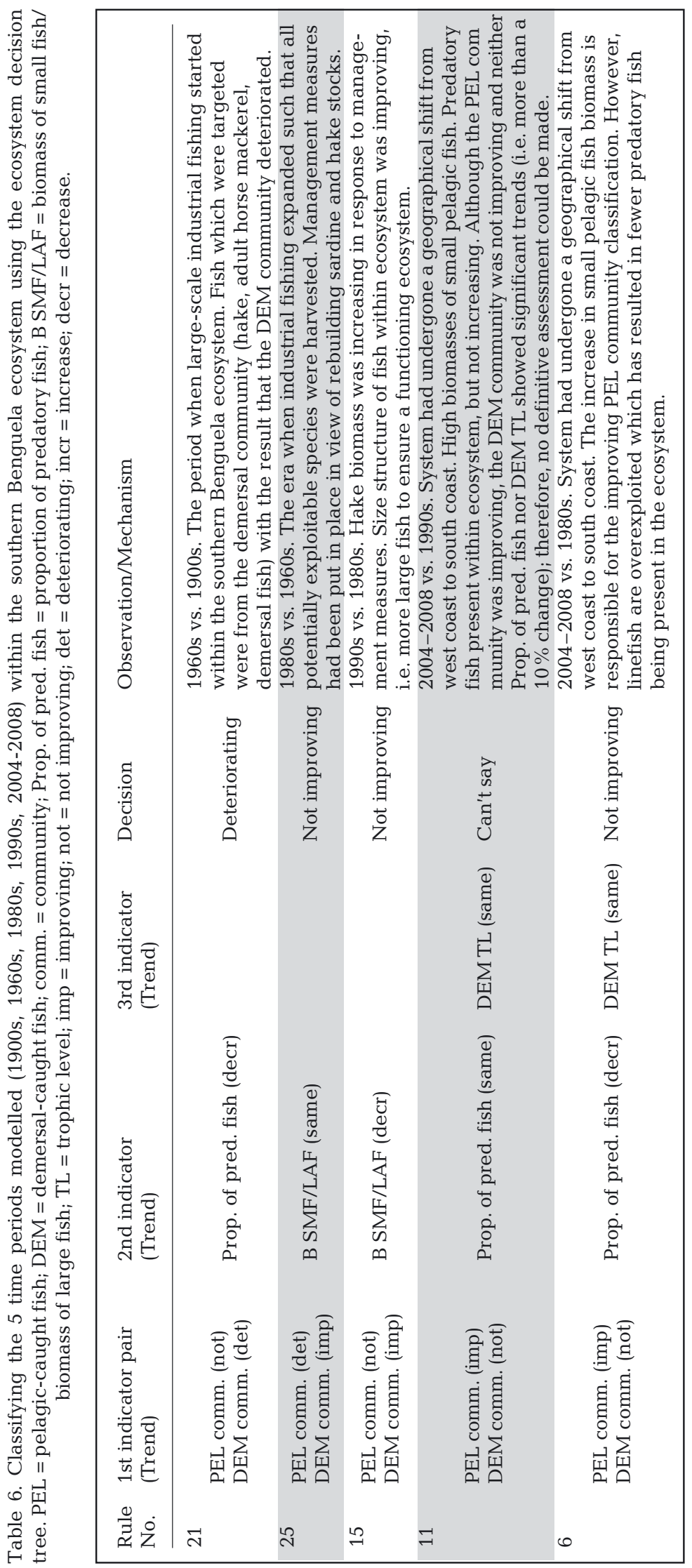

dances of anchovy and sardine. The 1900s and 1980s periods were modelled as anchovy-dominated periods. This explains the higher PEL TL and PLA TL during the 1900s and 1980s, since anchovy occupies a higher trophic level (average TL $=3.54$ ) than sardine (average TL $=2.95$ ). However, although anchovy is also the dominant small pelagic fish during the 2004-2008 period, sardine biomass increased 9-fold from the 1980s to the mid 2000s, and is responsible for the decline in TL of PEL and PLA.

As discussed by Watermeyer et al. (2008), mean TL of the catch showed a strong decline with the onset of industrial and new fisheries in the early 1900s. The mean TL of the catch increased slightly between 1960 and the 1980 s, but by the period 2004-2008, TL of the catch had declined again, and at higher resolution time scales there may be some warning signs (see Shannon et al. 2014, this Theme Section). The recent DEM and PIS catch indicators seem to suggest that the harvesting of these groups has remained constant and conservative since the 1960s, such that complete removal of the higher TL groups has not taken place. This is supported by the DEM, PIS and LAF biomass indicators which convey small recent increases. Conversely, the fisheries have shifted more towards lower trophic, small, planktivorous pelagic fish, since their abundance has increased dramatically in recent years as a result of a more favourable environment.

\section{Turnover rates (model output)}

Turnover rates describe ecosystem bioenergetics (Christensen 1995). Odum (1985) and Christensen (1995) propose that the turnover rates in mature systems would be low, since biomass has accumulated over time as a result of the efficient conversion of energy into biomass. Turnover rates of functional groups can therefore be used to determine whether a system is under stress (Odum 1985, Christensen 1995). Thus, it would seem that the demersal fish community of the southern Benguela eco- 


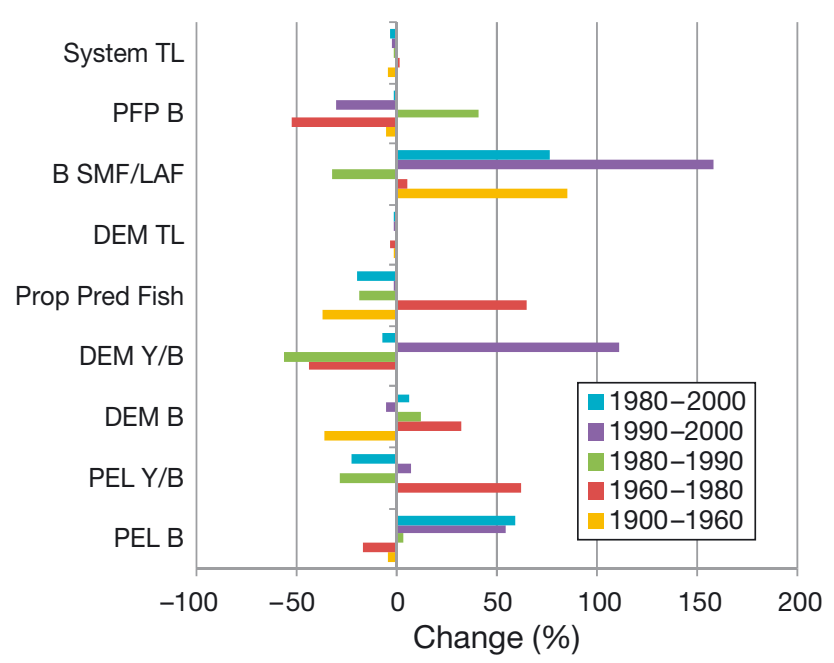

Fig. 10. Relative change in the decision tree indicators between 5 modelled periods. Note that catches of pelagic and demersal were insignificant in the 1900s and thus changes are only shown from 1960 onwards. TL $=$ trophic level ${ }_{;} \mathrm{B}=$ biomass; $\mathrm{Y}=$ catch. See Table 2 for species included in functional groups plotted

system has deteriorated since the 1960 s, and is possibly deteriorating further. Atkinson et al. (2012) has confirmed 2 shifts in the demersal fish community in the southern Benguela ecosystem. The first of the shifts occurred in the 1990s (increasing fish density) and the second in the mid-2000s (decreasing fish density). The shifts observed by Atkinson et al. (2012) reinforce the changing turnover rates of the PIS functional group observed in this study, and thus the changing demersal fish community of the southern Benguela ecosystem.

\section{Selection of trophic indicators for assessing the status of the southern Benguela ecosystem}

A simplified but complimentary suite of indicators is needed for management within the southern Benguela ecosystem. The indicators need to effectively capture the observed changes within the southern Benguela ecosystem, without losing any information through over-aggregation. The indicator groups presented above were examined for their ability to detect change within the southern Benguela ecosystem, and those deemed suitable were selected for consideration in formulating decision trees to assess ecosystem status (Table 3). Several sets of indicators examined were rejected as the reasoning for their inclusion in decision trees (i.e. decision rule formulation) was unclear. None of the production indicators were included because they display the same trend as the biomass indicators. In the absence of periodic productivity updates, it is simpler to use the biomass indicators, since they are likely to be more easily understood by stakeholders. Similarly, no consumption indicators were finally selected because either they included the plankton groups which are poorly quantified in the model, or it was unclear what would be needed by the decision tree model to clarify the consumption patterns of the components within the southern Benguela ecosystem. Pauly \& Watson (2005) encourage the use of a marine trophic index, with a cut-off TL of 3.25 for fish, when attempting to detect fishing down food web effects within an ecosystem. This indicator is applicable in global ecosystem comparative studies. However, in this study, indicator selection aimed to capture important dynamics of the southern Benguela ecosystem, an upwelling ecosystem that is dominated by mid-trophic level fishes such as anchovy (TL $=3.54$ ) and sardine ( $\mathrm{TL}=2.99)$, and which also extends over a shallow bank supporting a diverse demersal fish community (Shannon et al. 2009a). Mean TL of the demersal community, rather than mean TL of Y or the marine trophic index, was used as a warning signal for possible fishing down food web (Pauly et al. 1998) effects in this system.

\section{Assessing the status of the southern Benguela ecosystem using decision trees}

This was the first attempt at developing decision trees specific to the southern Benguela ecosystem. Emphasis was placed on the reasons for indicator use and the interpretation of trends, rather than applying statistics to try and validate significant trends. Use of 2 community-level decision trees and an overall system-level decision tree facilitates detection of warning signals regarding species or functional groups. For the southern Benguela ecosystem, half of decision outcomes obtained in all 3 decision trees were Not improving, suggesting that the first prototype of the decision trees and the associated indicators is conservative and robust. This classification agrees with that of Bundy et al. (2010) for the southern Benguela ecosystem, when their decision tree built on a $20 \mathrm{yr}$ time series of generic data-based indicators is applied and the rule of 2 negative trends is adopted for classification of an ecosystem as deteriorating. Conditions for an Improving/Deteriorating outcome were stringent, and if the community or ecosystem started in a 'good' situation, a Not improving classification would make 
the most sense. The question arises regarding how good a Not improving situation is, since the trends are all relative to a predetermined standard of what is thought to be a desirable situation (e.g. the 1900s). This first decision tree prototype specific to the southern Benguela ecosystem demonstrates the principles of use of the indicators in line with current understanding. As our understanding of community and ecosystem indicators improves, reference levels should be developed that will be reflected in later versions of the decision trees.

Importantly, a Not improving classification for either the community or ecosystem does not imply that all species or functional groups are in a good condition. In fact, the decision tree classifies the community and ecosystem in terms of the bigger picture, i.e. overall functioning of the community and ecosystem. Vigilance is required on the part of scientists, fisheries managers and stakeholders with regard to Not improving trends to constantly monitor the fish communities and overall ecosystem processes, because changing environmental conditions or fishing practices could negatively affect the individual species and/or functional groups within the community and/or ecosystem. The additional mortality of hake in the northern Benguela ecosystem due to a low oxygen event (Hamukuaya et al. 1998), reflected in benthic community analyses (Mafwila 2011) is a case in point.

Since a continuous time series of data was not used in this study, the significance of a trend displayed by an indicator and the decision tree could not be assessed statistically. Indeed, this form of statistical analysis did not form part of the objective when developing this decision tree. The decision trees are intended as communication tools between and amongst scientists, fisheries managers and other stakeholders.

\section{A STEP-WISE PROCESS TO EXAMINE CHANGES IN THE SOUTHERN BENGUELA ECOSYSTEM FOODWEB}

Ecosystem modelling is one of the tools used to inform the ecosystem approach to fisheries (EAF). In particular, trophic (food web) models are based on the interactions between ecosystem components, and therefore represent the complexity of food webs within an ecosystem. They provide information that can enable scientists, managers and other stakeholders to view the connections between and among the different functional groups, and assess how pres- sures-be they environmental or anthropogenicmay be affecting the ecosystem as a whole, as well as its individual components. However, this information largely remains untapped and needs packaging in a form that is accessible and meaningful to the stakeholders in question. Distillation of scientific results and literature into a form that is most appropriate and usable for fisheries managers and stakeholders is challenging but much needed for development of an EAF. In this study, a 3 step process was employed. (1) Building on Watermeyer et al. (2008), a series of snapshots of the southern Benguela ecosystem from the largely unfished era (1900s) to the 2000s was used to explore changes in the food web structure over time. (2) Trophic indicators were extracted from these models to detect changes. Those model-based indicators which were deemed most meaningful for communicating ecosystem changes to managers in the southern Benguela ecosystem were selected for use within Step (3), namely the development of decision trees to assess trends in ecosystem status as a result of fishing. The decision trees examined the southern Benguela ecosystem on a different scale to that which is currently addressed within management, i.e. focus was placed on the community (pelagic-caught fish and demersal-caught fish community decision trees) and system perspectives (ecosystem decision tree) of the southern Benguela ecosystem, in an attempt to complement the singlespecies assessments already in operation in South Africa.

A further step in the decision tree development process would be the presentation of decision trees to fisheries managers to generate feedback regarding its usefulness and clarity. Software is available to computerize the decision trees into 'expert systems' to include the underlying explanations in each step of the process, for easy communication to stakeholders. Weighting of indicators should be exploredfor example, according to information content being largely based on model input versus model output values and confidence in the various estimates. Further, sensitivity of ecosystem assessments should be tested by adopting different thresholds to classify trends in indicators as increasing or decreasing (in addition to the arbitrarily selected level of $10 \%$ change in indicators, as used in this first prototype). It is possible that different thresholds may be more suited to each indicator in the decision trees. This is an important aspect of future work needed to fine tune and improve the decision trees presented. In addition, variability in model parameters to account for uncertainties in parameterisation relating to data 
quality, availability or survey biases, should be examined to test the sensitivity of the decisions (classification of trends) based on model-derived trophic indicators. Along these lines, work under the auspices of the IndiSeas working group (www.indiseas. org) is underway (Shin et al. 2012). Further, development of reference levels for the indicators selected from this study is seen as a research priority for the future.

Acknowledgements. This work is supported through the South African Research Chair Initiative, funded through the South African Department of Science and Technology (DST) and administered by the South African National Research Foundation (NRF). In addition, W.O. gratefully acknowledges financial support from the Solm Yach Fellowship, the Harry Crossley Postgraduate Scholarship and the KW Johnstone Research Scholarship. C. Attwood (University of Cape Town, UCT), M. Gibbons (University of the Western Cape), K. Jolly (UCT) and K. Watermeyer (UCT) are thanked for sharing their research, data and expertise. The authors are grateful to the Department of Agriculture, Forestry and Fisheries (DAFF) and the Department of Environmental Affairs (DEA), and the following are sincerely thanked for providing data for model construction: R. Cooper (DAFF), R. Crawford (DEA), T. Fairweather (DAFF), S. Kirkman (DEA), R. Leslie (DAFF), C. van der Lingen (DAFF) and J. van der Westhuizen (DAFF).

\section{LITERATURE CITED}

Atkinson LJ, Jarre A, Shannon LJ, Field JG (2012) Evidence for shifts in demersal fish populations on the west coast of South Africa: 1986 to 2009. In: Kruse GH, Browman HI, Cochrane KL, Evans D and others (eds) Global progress in ecosystem-based fisheries management. Alaska Sea Grant, University of Alaska Fairbanks, p 45-64

Bundy A, Shannon LJ, Rochet MJ, Neira S, Shin YJ, Hill L, Aydin K (2010) The good(ish), the bad and the ugly: a tripartite classification of ecosystem trends. ICES J Mar Sci 67:745-768

Caddy J, Rodhouse P (1998) Cephalopod and groundfish landings: evidence for ecological change in global fisheries? Rev Fish Biol Fish 8:431-444

Christensen V (1995) Ecosystem maturity-towards quantification. Ecol Model 77:3-32

> Christensen V, Walters C (2004) Ecopath with ecosim: methods, capabilities and limitations. Ecol Model 172:109-139

Christensen V, Walters CJ, Pauly D (2005) Ecopath with ecosim: a user's guide. Fisheries Centre, University of British Columbia, Vancouver

> Cochrane KL, Augustyn CJ, Cockcroft AC, David JHM and others (2004) An ecosystem approach to fisheries in the southern Benguela context. Afr J Mar Sci 26:9-35

> Cochrane KL, Augustyn CJ, Fairweather T, Japp D and others (2009) Benguela Current large marine ecosystem-governance and management for an ecosystem approach to fisheries in the region. Coast Manag 37: 235-254

> Collie JS, Richardson K, Steele JH (2004) Regime shifts: Can ecological theory illuminate the mechanisms? Prog Oceanogr 60:281-302
Cury P, Shannon L (2004) Regime shifts in upwelling ecosystems: observed changes and possible mechanisms in the northern and southern Benguela. Prog Oceanogr 60: 223-243

- Cury PM, Shannon LJ, Roux JP, Daskalov GM, Jarre A, Moloney CL, Pauly D (2005) Trophodynamic indicators for an ecosystem approach to fisheries. ICES J Mar Sci 62:430-442

Daan N, Christensen V, Cury PM (eds) (2005) Quantitative ecosystem indicators for fisheries management. ICES J Mar Sci 62(3):307-310

> Degnbol P, Jarre A (2004) Review of indicators in fisheries management - a development perspective. Afr J Mar Sci 26:303-326

> Demarcq H, Richardson AJ, Field JG (2008) Generalised model of primary production in the southern Benguela upwelling system. Mar Ecol Prog Ser 354:59-74

Fairweather TP, van der Lingen CD, Booth A, Drapeau L, van der Westhuizen JJ (2006) Indicators of sustainable fishing for South African sardine Sardinops sagax and anchovy Engraulis encrasicolus. Afr J Mar Sci 28:661-680

FAO (2003) Fisheries management. 2. The ecosystem approach to fisheries. FAO Technical Guidelines for Responsible Fisheries 4(Suppl 2). FAO, Rome

FAO (2005) Putting into practice the ecosystem approach to fisheries. FAO, Rome

> Fulton EA, Smith ADM, Punt AE (2005) Which ecological indicators can robustly detect fishing? ICES J Mar Sci 62: 540-551

Gibbons MJ, and 64 others (1999) The taxonomic richness of South Africa's marine fauna: a crisis at hand. S Afr J Sci 95:8-12

> Griffiths MH (2000) Long-term trends in catch and effort of commercial linefish off South Africa's Cape province: snapshots of the 20th century. S Afr J Mar Sci 22:81-110

Hamukuaya H, O'Toole MJ, Woodhead PMJ (1998) Observations of severe hypoxia and offshore displacement of Cape hake over the Namibian shelf in 1994. S Afr J Mar Sci 19:57-59

> Howard JAE, Jarre A, Moloney CL (2007) Application of the sequential $t$-test algorithm for analysing regime shifts to the southern Benguela ecosystem. Afr J Mar Sci 29: 437-451

Kirkman SP (2010) The cape fur seal: monitoring and management in the Benguela current ecosystem. PhD thesis, University of Cape Town

> Lipinski M (1992) Cephalopods and the Benguela ecosystem: trophic relationships and impact. S Afr J Mar Sci 12: 791-802

> Lipinski M, Payne A, Rose B (1992) The importance of cephalopods as prey for hake and other groundfish in South African waters. S Afr J Mar Sci 12:651-662

Mafwila SK (2011) Ecosystem effects of bottom trawling in the Benguela Current System: experimetal and retrospective data analyses. PhD thesis, University of Cape Town

> Odum EP (1985) Trends expected in stressed ecosystems. Bioscience 35:419-422

Osman W (2010) Trophic model-generated indicators of the southern Benguela ecosystem for communicating with fisheries managers. Masters thesis, University of Cape Town

Pauly D, Watson R (2005) Background and interpretation of the 'Marine Trophic Index' as a measure of biodiversity. Philos Trans R Soc Lond B Biol Sci 360:415-423 
Pauly D, Christensen V, Dalsgaard J, Froese R, Torres F Jr (1998) Fishing down marine food webs. Science 279: 860-863

Pauly D, Christensen V, Walters C (2000) Ecopath, Ecosim, and Ecospace as tools for evaluating ecosystem impact of fisheries. ICES J Mar Sci 57:697-706

Polovina JJ (1984) Model of a coral reef ecosystem. I. The ECOPATH model and its application to French Frigate Shoals. Coral Reefs 3:1-11

Rand RW (1952) Fur seals: research and management. Commerce and Industry 11:35-40

Rand RW (1972) The Cape fur-seal Arctocephalus pusillus. 4. Estimates of population size. Investigational Report 89, Division of Sea Fisheries, Cape Town

Rothschild BJ, Shannon LJ (2004) Regime shifts and fishery management. Prog Oceanogr 60:397-402

Roy C, van der Lingen CD, Coetzee JC, Lutjeharms JRE (2007) Abrupt environmental shift associated with changes in the distribution of Cape anchovy Engraulis encrasicolus spawners in the southern Benguela. Afr J Mar Sci 29: 309-319

Shannon LJ, Moloney CL, Jarre A, Field JG (2003) Trophic flows in the southern Benguela during the 1980s and 1990s. J Mar Syst 39:83-116

Shannon V, Hempel G, Malanotte-Rizzoli P, Moloney C, Woods J (2006) Benguela: predicting a large marine ecosystem. Large Marine Ecosystem Series 14, Elsevier, Amsterdam

Shannon L, Coll M, Neira S (2009a) Exploring the dynamics of ecological indicators using food web models fitted to time series of abundance and catch data. Ecol Indic 9: 1078-1095

Shannon L, Jarre A, Schwing F (2009b) Regime shifts: ecological aspects. In: Steele JH, Thorpe S, Turekian K (eds) Encyclopedia of ocean sciences 2. Elsevier, Oxford, p 4329-4339

Shin YJ, Shannon LJ (2010) Using indicators for evaluating, comparing, and communicating the ecological status of exploited marine ecosystems. 1. The Indiseas project.

Submitted: November 13, 2013; Accepted: May 22, 2014
ICES J Mar Sci 67:686-691

Shin YJ, Shannon LJ, Bundy A, Coll M and others (2010) Using indicators for evaluating, comparing, and communicating the ecological status of exploited marine ecosystems. 2. Setting the scene. ICES J Mar Sci 67:692-716

Shin YJ, Bundy A, Shannon LJ, Blanchard JL and others (2012) Global in scope and regionally rich: an IndiSeas workshop helps shape the future of marine ecosystem indicators. Rev Fish Biol Fish 22:835-845

Slocombe DS (1998) Defining goals and criteria for ecosystem-based management. Environ Manag 22:483-493

Travers M, Shin YJ (2010) Spatio-temporal variability in fish-induced predation mortality on plankton: a simulation approach using a coupled trophic model of the Benguela ecosystem. Prog Oceanogr 84:118-120

van der Lingen CD, Coetzee JC, Hutchings L (2002) Temporal shifts in the spatial distribution of anchovy spawners and their eggs in the Southern Benguela: implications for recruitment. In: van der Lingen $C D$, Roy $C$, Fréon $P$, Barange $M$ and others (eds) Report of a GLOBECSPACC/IDYLE/ENVIFISH workshop on Spatial Approaches to the Dynamics of Coastal Pelagic Resources and their Environment in Upwelling Areas. GLOBEC Report 16, South African Journal of Marine Science, Cape Town, p 46-48

van der Lingen CD, Hutchings L, Field JG (2006) Comparative trophodynamics of anchovy Engraulis encrasicolus and sardine Sardinops sagax in the southern Benguela: Are species alternations between small pelagic fish trophodynamically mediated? Afr J Mar Sci 28:465-477

Watermeyer KE, Shannon LJ, Griffiths CL (2008) Changes in the trophic structure of the southern Benguela before and after the onset of industrial fishing. Afr J Mar Sci 30: 351-382

> Yemane D, Field JG, Griffiths MH (2004) Effects of fishing on the size and dominance structure of linefish of the Cape region, South Africa. Ecosystem approaches to fisheries in the Southern Benguela. Afr J Mar Sci 26: 161-177

Proofs received from author(s): August 28, 2014 